\title{
New Evidence on the Effects of the Shortened School Duration in the German States:
}

An Evaluation of Postsecondary Education Decisions

Tobias Meyer

Stephan L. Thomsen

Heidrun Schneider

No.01 


\title{
New Evidence on the Effects of the Shortened School Duration in the German States: An Evaluation of Postsecondary Education Decisions
}

\author{
Tobias Meyer* \\ Leibniz Universität Hannover \\ Stephan L. Thomsen ${ }^{\dagger}$ \\ Leibniz Universität Hannover \& ZEW Mannheim \& IZA Bonn \\ Heidrun Schneider ${ }^{\ddagger}$ \\ DZHW Hannover
}

This version: October 5, 2017

\begin{abstract}
Most German states have recently reduced the duration of university preparatory schooling from 13 to 12 years without changing the graduation requirements. We use nationwide data on high school graduates and the different timing of reform introduction in the federal states to identify the effects on postsecondary education decisions and to evaluate potential effect mechanisms. The results show that university enrollment of female students decreased in the first year after graduation in all analyzed states, whereas participation in voluntary service or staying abroad increased. Furthermore, students from non-academic families are more affected than students from an academic family background.
\end{abstract}

Keywords: school duration, learning intensity, postsecondary education decisions, Germany JEL Classification: I21, J18, C21

${ }^{*}$ Tobias Meyer, Leibniz Universität Hannover, Institut für Wirtschaftspolitik, Königsworther Platz 1, D-30167 Hannover, e-mail: tmeyer@wipol.uni-hannover.de, telephone: +49 511 762-14629, fax: +49 511 762-4574.

${ }^{\dagger}$ Stephan L. Thomsen, Leibniz Universität Hannover, Institut für Wirtschaftspolitik, Königsworther Platz 1, D-30167 Hannover, e-mail: thomsen@wipol.uni-hannover.de, telephone: +49 511 762-14596, fax: +49 511 762-4574; corresponding author.

${ }^{\ddagger}$ Heidrun Schneider, Deutsches Zentrum für Hochschul- und Wissenschaftsforschung (DZHW), Lange Laube 12, D-30159 Hannover, e-mail: h.schneider@dzhw.eu, telephone: +49 511450 670-155, fax: +49511450 670-960 


\section{Introduction}

The choice and definition of the optimal duration of schooling is a fundamental issue for education policy. On the one hand, the rising demands of the (academic) labor market require high-quality education that provides enough time for students to develop skills and to discover their own tastes and talents. On the other hand, earlier entry into the labor market is considered a more efficient use of (young) peoples' human capital; the resulting longer working life helps to ensure economic prosperity and the sustainability of the tax and social security systems. To solve the trade-off between the length of schooling and the length of labor market participation, the duration of university preparatory schooling in Germany has been reduced from 13 to 12 years over the past decade. Graduation requirements and the total number of lessons were not changed, however, which means that the curriculum was compressed into a shorter school duration. The main argument for this compression was that it would maintain the same level of education in a shorter period of time. Therefore, graduates should be enabled to commence their university education - and subsequently, their occupational careers - one year earlier.

However, the reform could have several possible effects. The notable increase in learning intensity (i.e., students must learn more curriculum per school year and per school week) and the shorter duration of schooling could either enhance or detract from the quality of education. A number of studies have shown that instructional time is causally related to school achievement. Longer school days improve achievement (e.g., Bellei, 2009), whereas a reduction of instructional time decreases performance (e.g., Marcotte, 2007; Krashinsky, 2014). Consequently, the reform in Germany could decrease school achievement and thus reduce the quality of university preparatory schooling. This effect has been identified by Büttner and Thomsen (2015) based on data from the state of Saxony-Anhalt. They find heterogenous effects with achievements in mathematics being reduced while those in German language being maintained due to the reform. However, there is little empirical evidence on the role of school duration and instructional time for education decisions following high school graduation. Several studies suggest that the content of the high school curriculum affects postsecondary education decisions. For example, Aughinbaugh (2012) and Falch et al. (2014) found that taking more math classes in high school increases enrollment in higher education. In addition, the time spent in school not only provides skills but also helps students discover their talents and preferences (Schultz, 1968). Because high school graduates affected by the reform enter postsecondary education at a younger age and with less life experience, they may be less prepared for making decisions about further education (cf. Malamud, 2011). Related evidence is provided by Meyer and Thomsen (2015). They analyzed the effects of the shortened school duration on perceived stress and extracurricular activities using data from the 2007 double cohort of high school graduates in the state of Saxony-Anhalt. The results show that students affected by the reform feel more burdened by learning and spent less time on working in a side job or voluntary activities. Based on extended data on the same reform, Meyer and Thomsen (2016) evaluated the effects on postsecondary education decisions. The study reveals gender-specific effects of the reform: whereas males' choices have not been affected, females have delayed university enrollment and increased participation in vocational 
education.

The present paper contributes to the findings of the scarce literature and the understanding of the impacts of the reform in a number of important ways. First, we evaluate the effects of the shortened school duration on postsecondary education decisions in several German states based on nationally representative data. These data comprise the graduation cohorts of 2006, 2008, 2010 and 2012 from the panel survey of high school graduates in Germany, conducted by the German Centre for Higher Education Research and Science Studies (DZHW, formerly HIS). Because the reform was not introduced nationwide but implemented separately in most states between 2001 and 2008 (with the first affected cohorts graduating between 2007 and 2016), we can use the difference in timing across states to identify causal effects. The effects are estimated by applying a difference-in-differences (DiD) approach, using varying definitions of the treatment and comparison groups. The estimation results provide comprehensive and quite general insights on whether and how education decisions made after graduating from high school are affected by a shorter school duration and higher learning intensity at school. Due to consideration of different federal states in the evaluation, we provide important results for generalizing the implications of the available evidence. Second, we further identify potential effect heterogeneity across states, which is relevant for education policy in the responsibility of the single states. Although the key elements of the reform were similar in all states, differences in the impact of the reform might occur due to differences in the manner of reform introduction, in the characteristics and socio-economic composition of the student body, or in the principal pattern of postsecondary education decisions. We make a particular effort to identify and validate these aspects in the empirical analysis. Third, we examine whether the reform affects students differently depending on the educational background of their families. Fourth, in addition to estimating the effects of the reform, we endeavor to investigate the underlying effect mechanisms. In this regard, the data provide information on several aspects of the decisionmaking process that allow us to test directly for these mechanisms.

Our findings reveal gender-specific effects of the reform. The probability of treated female students to be enrolled in university education in the first year after high school graduation significantly decreases by approximately 10 percentage points. When we also consider the firm intention to begin university education in the second year after graduation, the effect disappears. This result means that university enrollment is not reduced overall but rather delayed. The main reason for this delay is that the reform has increased the probability of engaging in voluntary service or spending a year abroad after high school graduation. A similar tendency can be observed in the male sample, but the effects are small and statistically insignificant. The identified effects are insensitive to various potentially confounding factors as demonstrated by several robustness checks. Importantly, the obtained results are not only applicable to the first affected cohorts but can also be considered to reveal permanent effects. Hence, our analysis can rule out the so-called implementation effects of the reform that have cast doubt on the validity of the empirical effects presented in the related literature. The analyses of effect heterogeneity show that the impact of the reform is similar across federal states. In contrast, there is effect heterogeneity with regard to socioeconomic composition: students are affected differently by the 
reform based on their respective family backgrounds. Although no significant effects are found for male students on average, male students coming from a non-academic family exhibit notably reduced university enrollment, and this effect lasts beyond the first year. Female students delay entry into postsecondary education regardless of their family background, but the pattern of decisions differs according to parental background. The key result from the investigation of the effect mechanisms is that the reform effects are caused less by insufficient preparation by the school or a higher degree of insecurity, but rather by the desire of affected students to take a break before continuing their education or to spend a year abroad or engaging in voluntary service.

The rest of the paper is organized as follows. The education system in Germany and the reform are described in section 2. The empirical approach is contained in section 3. Section 4 presents the results and robustness checks. Section 5 concludes the paper.

\section{The Reform}

\subsection{The Education System in Germany}

Although education policy in Germany is the responsibility of the federal states, it is nevertheless broadly similar across states. After four years of primary schooling, students are tracked into one of three secondary school types. The basic and intermediate tracks include schooling up to grade 9 and 10, usually followed by vocational education in the German apprenticeship system. The higher secondary school track (high school, Gymnasium) leads to the university admittance qualification (Abitur, allgemeine Hochschulreife), which is obtained - depending on state law - after a total of 12 or 13 years of schooling. In addition to completing high school, it is possible to obtain the university admittance qualification (or at least the qualification for admittance to universities of applied sciences) at vocational high schools or comprehensive schools. These schools represent only a small segment of the German school system. According to the Federal Statistical Office (various years a, b), approximately $7 \%$ of graduates obtain the university admittance qualification from comprehensive schools and $15 \%$ obtain it from vocational schools.

After graduation from high school, students can choose between two tracks of postsecondary education. According to numbers provided by Quast (2012), approximately 85\% of high school graduates choose university education, which can be classified into three categories: 1) studying at a university, 2) studying at a university of applied sciences, and 3) studying at a professional college. After three years, university education leads to a bachelor's degree, which is often followed by two additional years to obtain a master's degree. The bachelor's degree corresponds to an ISCED-2011 qualification level of 6, and the master's degree corresponds to a level of 7 (UNESCO, 2012).

The other track, which is chosen by nearly $25 \%$ of high school graduates, is vocational education (approximately 10\% of graduates participate successively in both vocational education and university (any type) thereafter). In the majority of cases, vocational education consists of an apprenticeship. The German apprenticeship system is quite unique from an international 
perspective and combines practical on-the-job training in a firm or in public service (where the trainee is employed) with part-time attendance at a vocational school. It typically takes approximately three years to complete. The German apprenticeship system is recognized as providing a high-quality education (OECD, 2010) and is classified as postsecondary non-tertiary education. A completed vocational education corresponds to an ISCED-2011 qualification level of 4 if the student has also obtained the university admission qualification; otherwise, it corresponds to a level of 3 .

The process of gathering information about postsecondary education possibilities and considering personal preferences and goals begins in the last three years of high school. Approximately $55 \%$ of students begin two or three years before graduation, whereas approximately $45 \%$ do not start this process before the final year of high school (Schneider and Franke, 2014, p. 25). To begin a vocational education, students must apply for their desired job several months before the intended start date, which is usually in August or September. To commence a university education, students must apply to their desired university for their desired subject. Some subjects in Germany have restricted admission; applications for these subjects must be submitted to the desired university by July for enrollment in October. In addition, a very small number of subjects (medical sciences and pharmacy) require an application to the Foundation for University Admission (Stiftung für Hochschulzulassung, formerly Zentralstelle für die Vergabe von Studienplätzen, ZVS). Other subjects, especially the so-called STEM subjects (which include natural sciences, technology, engineering and mathematics) can mostly be studied without restriction.

Some students take a year off between high school graduation and starting university or vocational education to engage in other activities, for example, to perform an internship or engage in voluntary service or spend a year abroad (approximately 15 to $25 \%$ of graduates, see Schneider and Franke, 2014, p. 121-122). Until 2011, males were principally obliged to enlist in military or civilian service for nine months, which often started shortly after school graduation.

\subsection{The Reform of School Duration}

The debate about the duration of university preparatory schooling has a long history in Germany. West Germany had a decades-long tradition of 13 years, which was increasingly called into question in the middle and late 1990s. This debate was supported by the fact that the East German states used a 12-year policy until the German reunification in 1990 (after reunification, most East German states adopted the West German system). As a consequence, between 2001 and 2008, most federal states eliminated the last year of high school (see Table 1). The only exceptions were Saxony and Thuringia, which had maintained the duration of 12 years following reunification, and Rhineland-Palatinate, which left its system of 12.5 years unchanged.

By and large, the implementation of the reform was similar across states. In all states, graduation requirements were maintained, which means that the curriculum was compressed into the shorter school duration. The reform implementation was completed in each state with the so-called double cohort of graduates, which included the first cohort graduating after the shorter school duration of 12 years and the last cohort graduating after 13 years. The first double cohort graduated in Saxony-Anhalt in 2007, followed by one or more other states in each 
Table 1: Introduction of the Shortened School Duration of 12 Years according to Federal State

\begin{tabular}{lcc}
\hline \hline & $\begin{array}{c}\text { Reform } \\
\text { Introduction }\end{array}$ & $\begin{array}{c}\text { Double Cohort } \\
\text { of Graduates }\end{array}$ \\
\hline Saxony (SN) & always 12 years & - \\
Thuringia (TH) & always 12 years & - \\
Saxony-Anhalt (ST) & 2003 & 2007 \\
Mecklenburg-Western Pomerania (MW) & 2001 & 2008 \\
Saarland (SL) & 2001 & 2009 \\
Hamburg (HB) & 2003 & 2010 \\
Bavaria (BA) & 2004 & 2011 \\
Lower Saxony (LS) & 2004 & 2011 \\
Baden-Wuerttemberg (BW) & 2004 & 2012 \\
Bremen (BR) & 2004 & 2012 \\
Berlin (BE) & 2006 & 2012 \\
Brandenburg (BB) & 2007 & 2012 \\
North Rhine-Westphalia (NW) & 2005 & $2012-2014$ \\
Hesse (HE) & $2004-2006$ & 2016 \\
Schleswig-Holstein (SH) & 2008 & - \\
Rhineland-Palatinate (RP) & never 12 years & \\
\hline \hline a The double cohort includes the first cohort graduating after 12 years and the last cohort \\
graduating after 13 years of schooling. \\
b Hesse introduced the reform in three subsequent cohorts, depending on the school. Grad- \\
uation of the first affected cohort: 2012 (10\% of schools), 2013 (60\% of schools), 2014 \\
(30\% of schools). \\
The difference between the year of reform introduction and the year of the double cohort \\
varies across states, since the reform was introduced for the first affected cohorts in the \\
states in different grades. & & \\
& &
\end{tabular}

subsequent year (see Table 1). Despite these similarities, some differences should be noted. Although the first affected cohort in many states comprised students entering grade 5 (which is the first grade of the Gymnasium), some states introduced the change in higher grades. Furthermore, whether the reform applies exclusively to high schools or to both high schools and comprehensive schools depends on the state.

As a consequence of the reform, students had to learn the same curriculum within a shorter time period. Therefore, the learning intensity experienced at school (i.e., the amount of learning content per school year or school week) notably increased. This change could have positive as well as negative effects. If it improves the efficiency of learning and the ability to cope with academic requirements, postsecondary education decisions should not be affected or more students could choose university education or challenging university subjects. However, the change could also be detrimental for learning outcomes, for example, if it overtaxes students or leaves fewer possibilities to teach and revise the learning content with the necessary depth. Consequently, students could be or could feel less prepared for university and may choose a less demanding track or subject in their postsecondary education.

Postsecondary education decisions may also be influenced by the reform through another channel. Due to the shorter school duration and the younger age at graduation, students have one year less to get to know their own abilities and to develop occupational preferences. Therefore, the insecurity about what to do after graduation might increase, which could in turn extend the period of time between graduation and entry into postsecondary education or could 
lead more students to start with a less demanding course of postsecondary education.

The empirical evidence available to date confirms several of these hypothesized implications of the reform but is also limited in several respects (see Thomsen, 2015, for an overview). Büttner and Thomsen (2015) found a negative effect on achievement in mathematics at the end of high school in Saxony-Anhalt. Related results by Hübner et al. (2017) for BadenWuerttemberg show a decrease of school achievements in biology and English reading. Huebener and Marcus (2017) report an increase in grade repetition. Analyses of personality traits show only small (Thiel et al., 2014) or ambiguous effects (Dahmann and Anger, 2014). Using data from Saxony-Anhalt, Meyer and Thomsen (2016) identify a later (but not lower) enrollment of female students in university education. Preliminary findings by Marcus and Zambre (2016) indicate delayed university enrollment. Regarding success at university, the study by Kühn (2014) shows that the reform has had no reasonable impact. Meyer and Thomsen (2017), in addition, find a few shifts at the intensive margin (measured by subjective perceptions of motivation and abilities), but these changes are not large enough to have an impact on the extensive margin, i.e., on the probability of university drop-out, graduation, and skill achievement in terms of final grades. Thus far, the available evidence - especially the evidence regarding the effects on outcomes after high school graduation - is based on specific states. Whether the identified effects are generally valid and, in particular, whether they hold for other federal states will be analyzed in the following sections.

\section{Empirical Approach}

\subsection{The Data}

For the empirical analysis of reform effects on postsecondary education decisions, we use data on high school graduates from all German states provided by the German Centre for Higher Education Research and Science Studies (DZHW). Every two or three years since 1976, the DZHW has surveyed students from randomly selected schools in all federal states (approximately $12 \%$ of all high schools). Since 2006, the surveys have been conducted as short panels with a first wave conducted six months prior to high school graduation. Students are asked in a written questionnaire about their experiences in high school, their plans after graduation, the process of information collection and related problems. In a second wave conducted six months after graduation, the same students are asked about the postsecondary education they have already started or firmly plan to start. The final and third wave for each cohort is conducted three and a half or four and a half years after graduation and is used to update the observations on postsecondary education $\sqrt{1}$

The data used in this paper include the 2006, 2008, 2010 and 2012 cohorts of graduates. Data from the third wave are currently available for only the 2006 and 2008 cohorts. Thus, postsecondary education decisions can be investigated only with respect to the time period of six months after school graduation. Despite this relatively short time horizon, education plans are

\footnotetext{
${ }^{1}$ A description of the data collection (in German) can be found, for example, in Schneider and Franke (2014).
} 
sufficiently concrete at that point in time. Data from the 2006 and 2008 cohorts show that $93 \%$ of students who state in the second wave that they firmly plan to enroll in university education have realized this plan three or four and a half years after graduation and that another $3 \%$ still firmly plan to attend university. The high correspondence between plans and realization is further supported by Ajzen (1991), who showed that an intention is a basic precondition and usually a reliable predictor of eventual action. Therefore, information provided six months after school graduation can be considered to represent the educational pathways of students in at least the first two to three years after graduation and to allow a meaningful evaluation of the reform effects.

The DZHW data are subject to panel attrition between the first and the consequent waves of each panel. The major reason for the panel attrition is a change of the survey methods used for data collection between the first and the following waves. The first wave of each panel takes place in classrooms and, thus, reaches almost every sampled student. Data from the first wave (half a year before graduation) are therefore representative for the population of close-tograduation students in Germany with respect to states, school types, and gender, and provide the most informative source on this group since representative administrative data comprising the same level of detail are not available. For the second and third waves, written questionnaires sent by mail are used. Hence, due to lower response rates in the mail surveys, the numbers of observations drop quite strongly. In addition, the response patterns differ between genders. Nevertheless, these drops are not associated with systematic changes of the socio-demographic composition but occur rather randomly. We will discuss more details and potential limitations below.

For the identification of the treatment effects, some modifications of the data are necessary. Since the DZHW data do not provide a direct indicator of whether the person is enrolled in a 12- or a 13-year school-track for cohorts of school leavers before the year 2010, the imposed data restrictions are necessary to carefully distinguish treated and non-treated individuals in the same way for all included cohorts. This distinction between groups is based on the institutional settings in place in the states and at the points of time considered. Students who did not graduate from high school (but graduated, e.g., from comprehensive schools or vocational high schools) or who did not obtain the general university admittance qualification (but obtained, e.g., only the qualification for admittance to universities of applied sciences) are excluded because the reform does not apply to vocational high schools, integrative comprehensive schools and, in some states, cooperative comprehensive schools. We further exclude students who do not belong to the respective birth cohorts to minimize the confounding influences of atypical school durations and student ages $2^{2}$ Thus, students with early or late school enrollment, grade repetition or grade skipping, who account for approximately 15 to $20 \%$ of the original sample, are not considered. This procedure also ensures that all students in the sample are of age at the time of their high school graduation.

We have checked for different sample definitions and have re-estimated all models specified

\footnotetext{
${ }^{2}$ The cut-off birth date for a school year in Germany is 30 June. Hence, students in a given cohort are usually born between 1 July of the respective year and 30 June of the following year. Only these students are included.
} 
below accordingly (results not presented). These alternative definitions comprise, besides others, a sample without restriction of the birth cohort (including all types of late or early enrollment, grade repetitions, etc.) and a sample with a more relaxed restriction of birth cohorts (covering the whole calendar years of the relevant birth cohort). Quantitatively as well as with respect to statistical significance, the results do no change. Vice versa, the exclusion of observations from the sample as required for identification of clear treatment effects does not change the estimation results. Moreover, since the data provide no means to further distinguish reasons (including effects of the reform) for deviations from the birth interval of the majority of students, we prefer the definition above because it allows a reliable interpretation of the estimated treatment effects.

The final estimation sample contains 5,383 observations in 2006, 10,380 in 2008, 9,353 in 2010 and 13,374 in 2012 of students who participated in the first survey six months before graduation. Because the data are affected by panel attrition, not all students participated in the second wave of the survey. Information about postsecondary education decisions is available for only 2,855 observations in 2006, 3,005 observations in 2008, 3,582 observations in 2010 and 5,690 observations in 2012. Due to different response rates by gender, the original data of the second wave have an overrepresentation of women, i.e., the attrition in the data provided by the DZHW differs by gender. Importantly, the relative changes in the gender proportions in the edited data compared to the original DZHW data (1st and 2nd wave) are in all cases below 2.5 percentage points (.86 percentage points in $2006 ; 2.41$ in $2008 ; 2.15$ in $2010 ; 1.97$ in 2012). Potential sample selection bias induced by the applied data modifications therefore should hardly impose a problem for the empirical analysis.

To address concerns about a potential panel attrition bias, Table A.1 in the appendix shows mean values of student characteristics in the samples of the first and second waves. For most variables, mean values are very similar in both waves, indicating that a bias is unlikely to exist. There are only a few exceptions: students planning to start university education, students with a better assessment of their career prospects, and students with better grades are a bit more likely to participate in the second wave. This is not surprising because several studies show that high-achieving students are more likely to participate in a survey than low-achieving students (e.g., Porter and Whitcomb, 2005). More importantly, this pattern exists similarly in the female and male samples. However, the few statistically significant differences, which can be observed in Table A.1, are very small in size (e.g., the differences of 0.07 and 0.05 regarding the average grade at high school is small, given that grades range between 1.0 and 4.0) and should therefore not be a concern of the estimated reform effects 3

Enrollment in university and vocational education is observed six months after school graduation and is analyzed in two dimensions. A first binary variable indicates actual enrollment, whereas the second dummy indicates whether a student is actually enrolled or firmly plans to enroll in university or vocational education as his or her first postsecondary education (e.g.,

\footnotetext{
${ }^{3}$ Given the similarity of student characteristics between the first and second waves of the survey, we have no reason to assume that the data are affected by a panel attrition bias. Nevertheless, the DZHW provides a weighting factor that takes panel attrition into account. The factor is calculated on the basis of school types, gender, and state in the first wave. As a robustness check, we have re-estimated all models in the paper with consideration of the weighting factor. The results do not change, and we refrain from presentation and discussion.
} 
after having completed military, civilian or voluntary service or another activity in the year following graduation). To minimize a potential bias from uncertain plans and decisions, only students who have already decided on their postsecondary education are included in the second dummy variable. However, more than $97 \%$ of students have made this decision at the time of the survey, and in almost all cases, they intend to enroll one year after graduation 4

Moreover, three other activities in the year after high school graduation are captured covering (1) military or civilian service, (2) internships or temporary work, and (3) voluntary service or a year abroad. Finally, we distinguish the choice of university subject, which is measured with regard to actual and firmly planned university enrollment. University subjects are categorized into six groups: (1) humanities, (2) education and social sciences, (3) law and economics, (4) engineering, (5) natural sciences and mathematics, and (6) medical sciences. Due to the particular importance of engineering, natural sciences and mathematics (the so-called STEM subjects) for the economic prosperity of a highly developed and industrialized country such as Germany, these subjects are also considered as a group. Although medical sciences are contentrelated to STEM subjects, it is not clear whether they belong to this group. Therefore, STEM subjects are first considered in the analysis with a narrow definition (without medical sciences) and then considered with a broader definition (including medical sciences).

\subsection{Identification Strategy}

To evaluate the effects of the reform on postsecondary education decisions, we use a differencein-differences approach. The different timing of the introduction of the reform in the federal states provides regional variation that allows identification via a comparison of students who graduated under the old system (13 years of schooling) and students who graduated under the new system (12 years of schooling). Ten states completed the reform - i.e., the first students graduated from high school after 12 years of schooling - between 2007 and 2012 (see Table 11. We can use 2012 as the post-reform year and the cohorts 2006, 2008, and 2010 as the prereform periods. However, we concentrate on 2008 as the pre-reform year because the education decisions of the 2010 graduation cohort could be influenced by the upcoming double cohorts in two large federal states (Bavaria and Lower Saxony) in 2011. Students from the 2010 cohort had an incentive to accelerate their enrollment in postsecondary education to avoid competition with the double cohort. This did in fact take place in the case of female students (see Figure 2 in the next section). Hence, estimates based on 2010 as the pre-reform year could be biased due to anticipation effects. However, the 2008 cohort is not affected by these or other influences and thus can be used as the pre-reform period. Including the year 2006 is therefore not necessary; moreover, the longer period between 2006 and 2012 may potentially allow other unintended effects into our analysis.

\footnotetext{
${ }^{4}$ The question in the survey from which the variable firmly planned enrollment is obtained, contains three response categories: (1) "I have decided to enroll in university/vocational education (or to do something else)", (2) "I have not made a final decision, but I will probably enroll in university/vocational education (or do something else)", and (3) "I have absolutely no idea about my further education at this time". Only category (1) is considered in the variable on planned enrollment, albeit it contains almost all students. Fewer than $3 \%$ of students belong to categories (2) and (3).
} 
In the main specification, the years 2008 and 2012 represent the pre- and post-reform periods. The treatment group comprises the three West German states that completed the reform introduction in 2010 and 2011 - Bavaria, Hamburg, and Lower Saxony (treatment group 1). All other reform states are not included for the following reasons: Saxony-Anhalt and MecklenburgWestern Pomerania completed the reform in 2007 and 2008, i.e., before or in the pre-reform year. For the small state of Saarland (which completed the reform in 2009), no observations are available in 2012. Finally, the four states with a double graduation cohort in 2012 (BadenWuerttemberg, Berlin, Brandenburg, and Bremen) are not included because the first affected cohort could reflect a special situation, which may not be representative due to implementation effects. The comparison group contains the states that did not change the school duration during the observation period: Hesse5, Rhineland-Palatinate 6 , Schleswig-Holstein, Saxony, and Thuringia. Figure 1 and Table A.2 in the appendix present the composition of the treatment and comparison groups by federal state. North Rhine-Westphalia is not considered because the upcoming double cohort in 2013 increased the incentive for 2012 graduates from this state to accelerate their university enrollment (as in the abovementioned cases of Bavaria and Lower Saxony in 2010).

In addition, we estimate the reform effects with alternative definitions of the treatment group. First, we additionally include the states with a double cohort in 2012 (Baden-Wuerttemberg, Berlin, Brandenburg, and Bremen) in the treatment group (treatment group 2). Of course, we do not consider the entire double cohort in 2012 but only the students with 12 years of schooling. This treatment group definition can be viewed as a test of whether the results change if the first affected cohort is considered (for example, due to implementation effects or potentially increased competition for study places). As a second alternative, we use Saxony-Anhalt and Mecklenburg-Western Pomerania, which completed the reform introduction in 2007 and 2008, as treatment states (treatment group 3). The pre-reform year is defined as 2006. Because the 2012 cohort represents only the second or third affected cohort in Bavaria, Hamburg and Lower Saxony but the fifth or sixth affected cohort in Mecklenburg-Western Pomerania and Saxony-Anhalt, this treatment group is used to investigate whether potential effects occur only in the first years following the implementation of the reform or persist over the long-term. Another difference between treatment groups 1 and 3 is that the former focuses on the effects of the reform in West Germany, whereas the latter analyzes the impact of the reform in East Germany.

The causal effect of the reform is then estimated by the following difference-in-differences probit model:

$$
\operatorname{Prob}\left(E_{p, s, i}=1\right)=\Phi\left(\beta_{0}+\beta_{1} T R E A T G R_{i}+\beta_{2} P O S T_{i}+\beta_{3} D I D_{i}+\beta_{4} \mathbf{X}_{i}+\gamma_{s}\right) .
$$

\footnotetext{
${ }^{5}$ Hesse introduced the reform in three consecutive cohorts depending on the school. In $10 \%$ of the schools, the first affected students graduated in 2012, whereas in $90 \%$ of the schools, the first affected cohort graduated in 2013 or 2014. The small number of students graduating after 12 years of schooling in 2012 are not included in the sample.

${ }^{6}$ Rhineland-Palatinate has not introduced the reform but maintained its system with 12.5 years of schooling. However, in practice, its system provides 12.7 years of schooling and is therefore more similar to graduation after 13 years than to graduation after 12 years.
} 


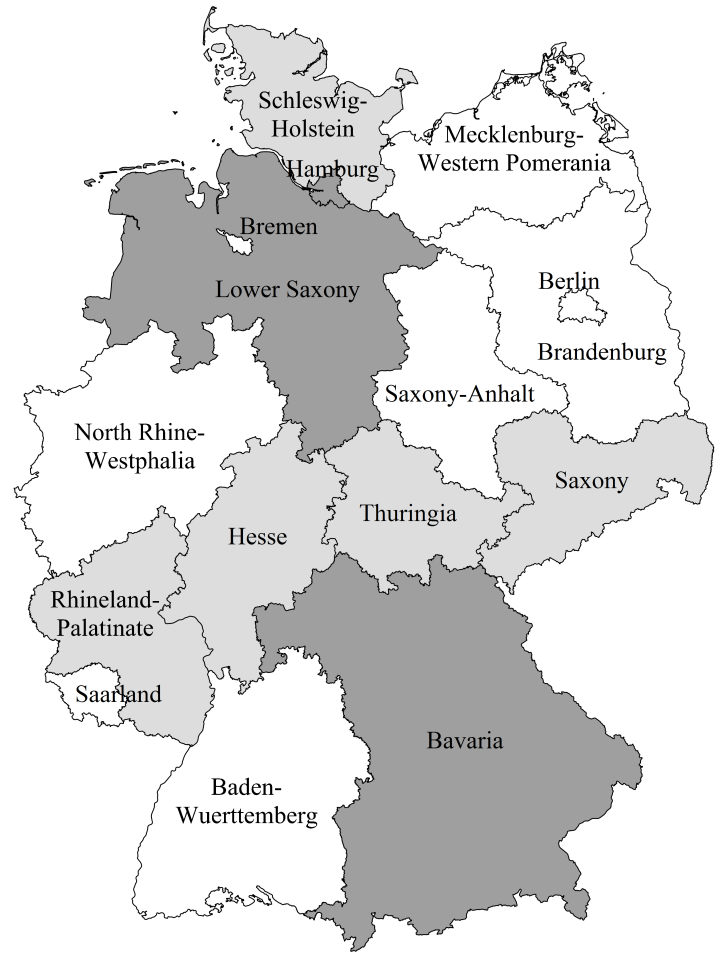

(a) Treatment Group 1

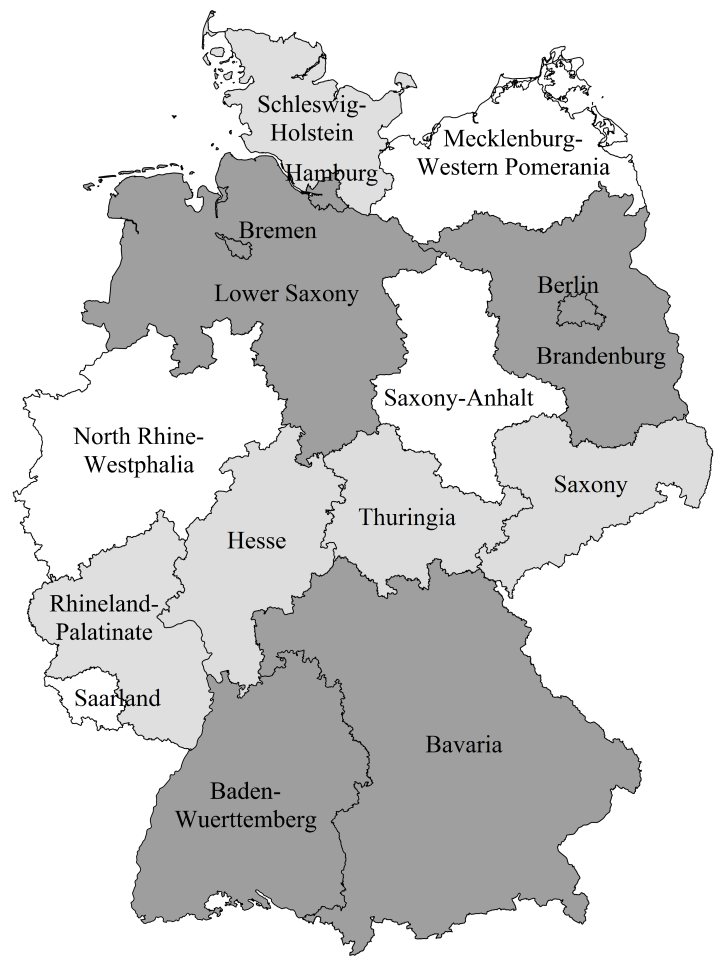

(b) Treatment Group 2

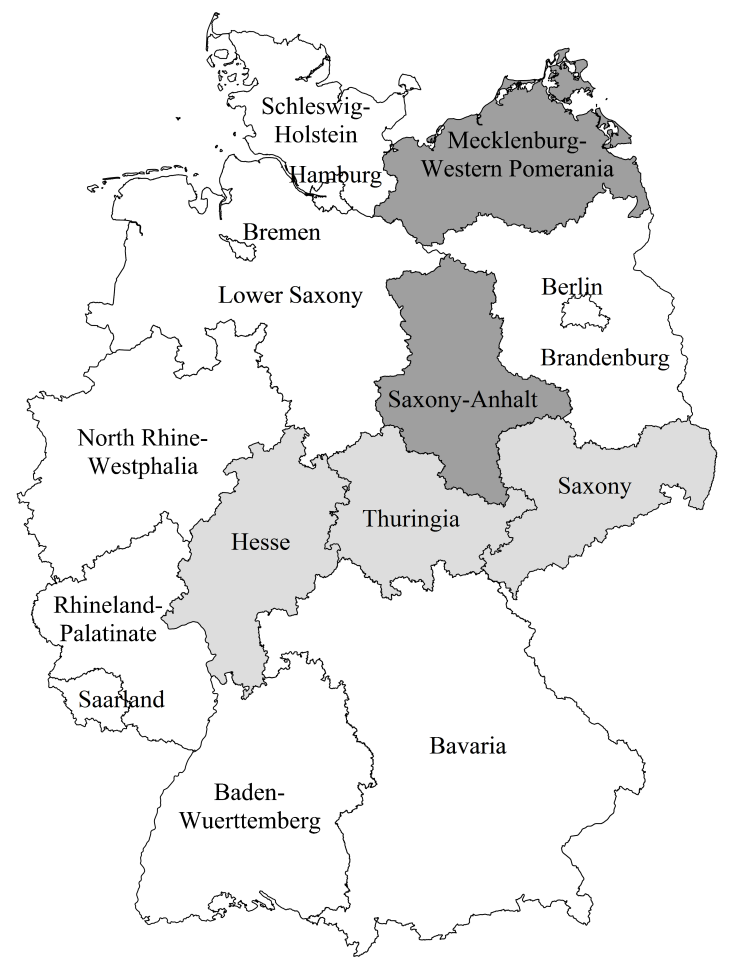

(c) Treatment Group 3

Figure 1: Treatment States (dark grey) and Comparison States (light grey) 
The binary outcome variable is denoted by $E_{p, s, i}$. Then, $\operatorname{Prob}\left(E_{p, s, i}=1\right)$ is the probability of individual $i$ from state $s$ being enrolled in a specific type of postsecondary education $p$ (i.e., university education, vocational education, several other activities in the year after high school graduation, and several university subjects). For each outcome, a separate model is estimated. On the right-hand side of equation (1), $\beta_{0}$ is the constant. TREATGR $R_{i}$ is a dummy variable that takes the value 1 if an individual belongs to the treatment group and takes the value of 0 if an individual belongs to the comparison group. Thus, the coefficient $\beta_{1}$ captures the non-reform difference between students from the treatment and comparison groups. POST $i$ indicates the time period and equals 0 for the pre-reform period (2008) and 1 for the postreform period (2012), with the coefficient $\beta_{2}$. The interaction term between TREATGR $i$ and $P O S T_{i}$ is denoted by $D I D_{i}$, which is equal to 1 if an individual belongs to the treatment group in the post-reform year. Puhani (2012) has shown that in nonlinear difference-in-differences models, the incremental effect of the coefficient of the interaction term represents the treatment effect. The marginal effect, derived from the corresponding coefficient $\beta_{3}$, indicates the impact of the reform, namely the average treatment effect (ATE).

To consider differences among years and groups and to increase the efficiency of the estimates, additional variables that influence postsecondary education decisions are included in the regression in $\mathbf{X}_{i}$. These are dummy variables that indicate whether at least one parent has an academic degree, whether the student has a migration background, and whether the student belongs to the older group of students in the respective cohort (i.e., born between 1 July and 31 December) $7^{7}$ In addition, the number of books owned by the parents and the current or most recent occupational position of the parents (measured by the International Socio-Economic Index of Occupational Status, ISEI; see Ganzeboom et al., 1992) are considered using two dummy variables for the middle and upper categories of each of the two categorical variables. Finally, state dummies $\gamma_{s}$ capture the influence of the federal state in which the student graduated from high school 8 The analysis is conducted separately for males and females because postsecondary education decisions differ by gender (see, e.g., Buchmann et al., 2008; for Germany see, e.g., Lörz et al., 2012) and the reform in Saxony-Anhalt showed different effects for males and females (Büttner and Thomsen, 2015; Meyer and Thomsen, 2016).

The general idea of the difference-in-differences approach can be summarized as follows: We compare the outcomes of high school graduates in 2008 (pre-reform) with those of high school graduates in 2012 (post-reform) in the treatment group (first difference). Then, we compare this difference with the respective difference in the outcomes of the comparison group, which is not affected by the reform. From this comparison (second difference), the causal effect of the reform is obtained. With this procedure, any common time trend between 2008 and 2012 as well as differences in student characteristics between the treatment and comparison groups are eliminated from the analysis.

\footnotetext{
${ }^{7}$ Several studies have shown that older students within a cohort exhibit better education outcomes than younger students. This relative age effect can persist beyond secondary schooling (Fredriksson and Öckert, 2014; Bedard and Dhuey, 2006; Crawford et al., 2010).

${ }^{8}$ Dummies are included for each state except one state from the treatment group and one state from the comparison group (reference states) due to multicollinearity with the treatment group indicator.
} 
As an alternative to the two-period approach, one could in principle also use the data from all four periods and states available. However, as mentioned above, the postsecondary education decisions of the 2010 cohort are influenced by anticipation effects due to the upcoming double cohorts in 2011 in Bavaria and Lower Saxony. Thus, only three periods remain, and using 2006 in addition to 2008 is of little benefit. On the contrary, the 2006 values of some outcome variables represent outliers in some states. Therefore, we concentrate on 2008 and the twoperiod framework $\square^{9}$

\subsection{Validity of the Identification Strategy}

Identification requires that there is no selection bias between treatment and comparison groups. This requirement can be assumed to be fulfilled because from the students' perspective, the reform was randomly introduced. The reform implementation took place within a short period of time in the respective states (especially in Bavaria and Hamburg) 10 Students had very few possibilities to evade the reform by, for example, moving or commuting to another state, switching to another type of school (in two of the three treatment states, it is still possible to graduate after 13 years at comprehensive schools), or skipping a grade. However, moving or commuting to another state would include very high monetary and non-monetary costs. Moving to another type of school would be easier, but official statistics from the Federal Statistical Office (various years a) do not indicate that more students in the treatment states moved to comprehensive schools relative to high schools (Gymnasium) after the introduction of the reform 111 Furthermore, the German education system normally does not provide the possibility of fast-tracking school by skipping a grade.

Thus, a selection bias may come only from increased grade retention, which is suggested by Huebener and Marcus (2017). To check this possibility, Table A.4 in the appendix presents the shares of students who dropped out of their respective cohorts in the last two years of high school based on official statistics from the Federal Statistical Office (various years a). Note that dropping out includes both grade retention and leaving the school track. Drop-out rates in certain federal states such as Bavaria and Hamburg have not risen, whereas an increase can be observed in other states (e.g., Berlin or Mecklenburg-Western Pomerania). For a third group of states, there is an increase but the timing does not correspond to the reform introduction. For example, in Lower Saxony, the increase started already in the 2008 graduation cohort. Therefore, using Bavaria, Hamburg and Lower Saxony as treatment states in our main treatment group should not be affected by increased grade retention. In any case, even if a selection bias exists, the estimated effects could be interpreted as lower bounds: because grade repetition is more likely to affect students with lower achievement, any detrimental effect of the reform would be underestimated.

Further assumptions that must be fulfilled for identification are the following (see, for ex-

\footnotetext{
${ }^{9}$ This approach has the advantage of avoiding the need to adjust standard errors for serial correlation of error terms, as it is necessary in DiD estimations with multiple periods (see Bertrand et al., 2004).

${ }^{10}$ Table A.3 in the appendix provides more information on the introduction of the reform in the states in treatment group 1.

${ }^{11}$ Also Huebener and Marcus (2017) do not find evidence for reduced high school attendance due to the reform.
} 
ample, Meyer, 1995). There should be no interaction between time and groups except for the treatment, i.e., any time trends must be equally present in both groups and any group effects must be constant over time. This assumption should hold here because the analyzed period contains only four years; during that time, social and macroeconomic conditions have not changed differently across states. Furthermore, student characteristics should not be too different between treatment and comparison groups and any changes in these characteristics should be similar between groups. We will further several checks in the next section.

However, an interaction between time and groups may occur if other education reforms have been introduced in the states at different points in time. Table A.5 in the appendix gives an overview of other reforms. The most likely reforms to exert an effect are changes in the high school system that have been implemented several years ago in certain states (e.g., central final examinations, earlier tracking, changed curriculum). Potential concerns can be mitigated since central final examinations have been conducted in many states for a long period of time and commenced in the remaining states no later than 2008. Tracking has not changed in the treatment and comparison states with the exception of Lower Saxony, where tracking was moved from grade 7 to grade 5 since the 2011 graduation cohort. Nevertheless, earlier tracking should not have a large effect on upper secondary schooling. The changes in the high school curriculum (e.g., restricted subject choices, additional examination subjects) vary across states in terms of content and timing. In some states, the changes were already in place in 2008, in other states, the changes were introduced for graduation cohorts between 2008 and 2012, and several states have made no changes to the high school curriculum. Although these reforms were not as substantial as the shortened school duration, the differences in the timing of the introduction could potentially confound the analysis. We will consider this issue in section 4.5 below.

A second reform that may have a confounding effect is the conversion of study programs to bachelor's and master's degrees (the so-called Bologna process). Effects are not expected since this reform was introduced almost simultaneously in all German states and was largely completed by 2008. The share of university entrants being enrolled in bachelor's programs was approximately $68 \%$ in 2008 and $77 \%$ in 2012 (the difference from $100 \%$ is due to the fact that certain study programs were not subject to the Bologna process). These numbers are identical for the subgroups of students in the treatment and comparison groups (cf. Schneider and Franke, 2014, p. 155-159). Similarly, the abolition of military service in 2011 equally affects students from treatment and comparison states (cf. Table 3 in the following section).

A last, potentially relevant reform is the introduction of university tuition fees in some states. However, in most states under investigation, tuition fees had either been introduced by 2008 and remained valid in 2012 or fees had not been introduced in either of the two years. Moreover, empirical evidence suggests that the introduction of university tuition fees in Germany had no influence on university enrollment (e.g., Helbig et al., 2012; Bruckmeier and Wigger, 2014). Thus, conditions for postsecondary education decisions could be assumed to be the same in both years, even in states that made changes in tuition fees.

A key assumption in any difference-in-differences analysis is that the outcomes for students in the treatment and comparison groups would follow the same time trend in the absence of 
the treatment. Although the counterfactual outcome is unobservable, similar pre-treatment trends could be seen as a verification of this common trend assumption. Figure 2 shows the shares of students who started (or firmly planned to start) university education after high school graduation between 2002 and 2012 ${ }^{12}$ The outcomes have similar values and show similar developments in both the treatment and comparison groups until the introduction of the reform, independently of actual and firmly planned enrollment. The only exception is females' actual enrollment in the year 2010; in that year, students in Bavaria and Lower Saxony had a considerable incentive to start university soon due to anticipation of the expected large number of high school graduates in the double cohort of 2011. Therefore, we exclude the 2010 graduation cohort from the analysis (see section 3.2 above). Enrollment trends move in parallel until 2008, which supports the common trend assumption.

Moreover, we conduct a gender-separated analysis to account and explicitly allow for different postsecondary education trajectories for males and females. Gender differences in these trends are likely for various reasons, e.g., changing gender compositions of cohorts over time, gender-specific tastes or preferences, military or civilian service for males, etc. Different common trends for genders impose no problem for our analysis, since we identify treatment effects within genders only. In this design, we have to assume a common trend for females independently of assignment to treatment and comparison group. Moreover, we assume a (different) common trend for males independently of assignment to treatment and comparison group. For identification of gender-specific effects, there is no need that these trends are identical.

An advantage of the identification strategy is that the analyzed students do not represent the first affected cohort (except for a portion of treatment group 2) to avoid implementation effects or temporary effects affecting the estimation results. These are possibly caused by the double cohorts in 2010 and 2011, but are less likely to remain in 2012. It is also not very likely that access to university education is restricted more than average in the analyzed states in 2012. According to official statistics from the Federal Statistical Office (various yearsc), the number of study places was increased in 2011 in Bavaria and Lower Saxony as well as in the neighboring states to take account of the larger number of university entrants from the double cohorts. In 2012, the situation in these states had largely returned to normal.

Furthermore, confounding influences from states with double cohorts in 2012 are unlikely to exist. The number of additional students from the small states of Berlin, Brandenburg, and Bremen is too low to have a significant influence on university places in the treatment and comparison groups (approximately 9,000 additional high school graduates compared to a total of approximately 305,000 high school graduates in Germany in 2012). Regarding the larger double cohort in Baden-Wuerttemberg, a significant influence on conditions for university enrollment in this and other states is not very likely because the number of study places in Baden-Wuerttemberg was increased by approximately 20,000 (State Ministry of Baden-Wuerttemberg, 2010) in light of the increase in the number of high school graduates by approximately 24,000 in 2012 (Federal Statistical Office, various years a). For this reason, the double cohort from Baden-Wuerttemberg

\footnotetext{
${ }^{12}$ The data for the 2002 and 2004 cohorts are used only for descriptive statistics.
} 

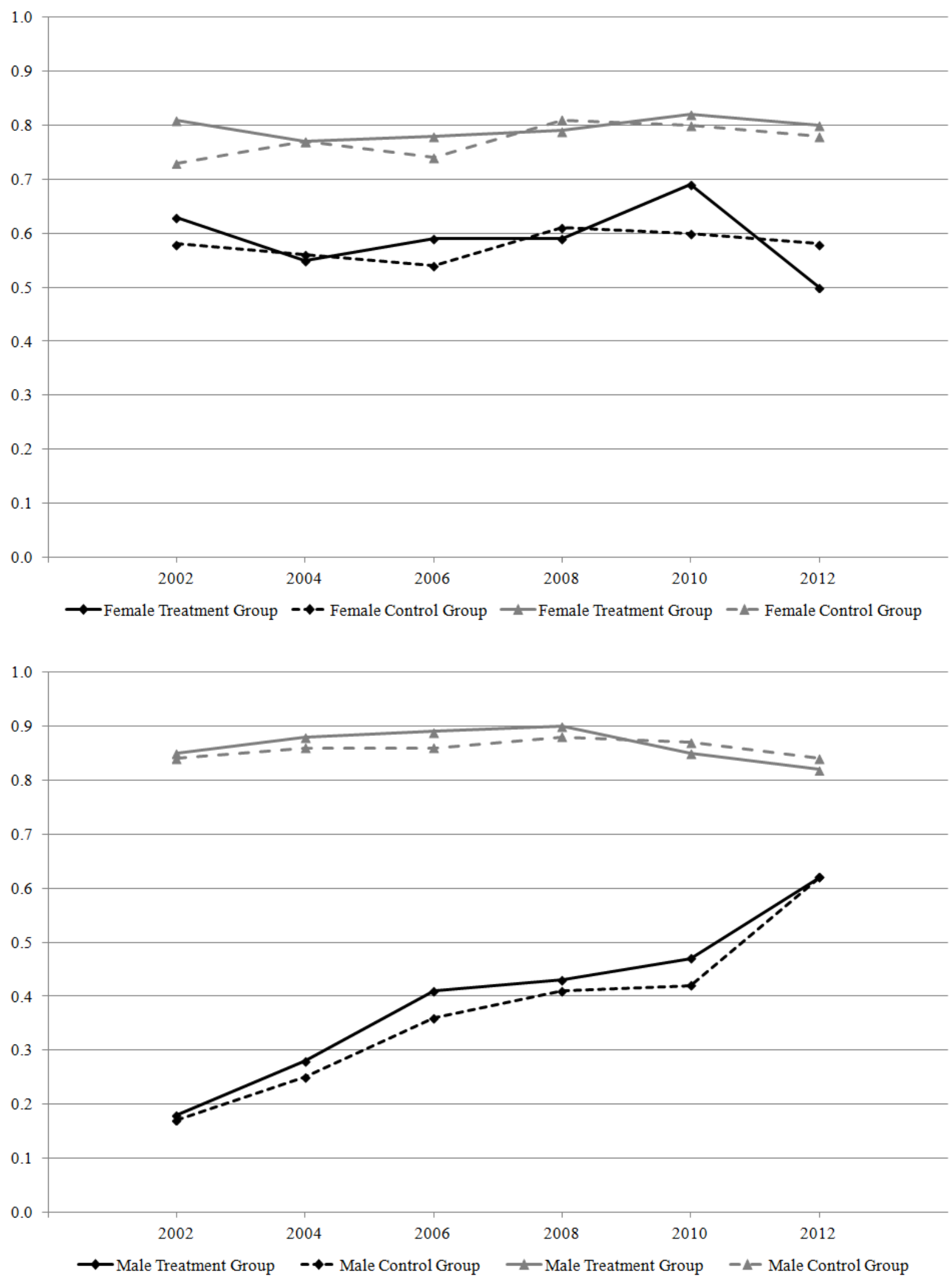

Figure 2: Share of Students enrolled in University Education (Actual Enrollment: Black; Actual and Firmly Planned Enrollment: Grey; Source: DZHW data, own calculation) 
should have had no systematic influence on the neighboring state of Bavaria. Indeed, the number of students from Baden-Wuerttemberg starting university in Bavaria in 2012 is not significantly higher than it was in 2010 (an increase of 650 students from Baden-Wuerttemberg compared to approximately 64,000 university entrants in Bavaria). Finally, and most importantly, if competition for study places had increased considerably due to the double cohorts, it should be visible in university admission grades. However, a comparison of admission grades at selected universities in Bavaria, Lower Saxony, and Baden-Wuerttemberg shows that grades remained relatively constant in most subjects between 2009 and 2012 (see Table A.6 in the appendix), which supports our conclusion that the double cohorts have not restricted university access more than average. 13

\subsection{Descriptive Statistics}

Table 2 contains a description of several characteristics of students in the treatment and comparison groups in the pre- and post-reform periods. The age of students appears to be equally distributed within cohorts. Approximately 10 to $15 \%$ of students have a migration background, which remains constant over time in the female groups and decreases equally in the male groups. The educational background of students is also similar for both groups and years. The share of students whose father or mother graduated from high school is approximately $50 \%$ in the female sample and approximately $55 \%$ in the male sample. There is a small time trend in the academic education of the parents (except for the male comparison group): slightly more students come from non-academic families in 2012 than in 2008. This difference could be due to the long-term trend of increasing social openness of high schools in Germany (see, for example, Trautwein and Neumann, 2008). The third indicator of students' educational background (number of books at the parental home) has a similar distribution and development between groups; only the share of students in the lowest category increased more in the female comparison group than in the treatment group. Finally, the occupational positions of the parents, as measured by the ISEI, is largely similar across time and groups.

Altogether, the high degree of similarity in observable characteristics between students in the treatment and comparison groups indicates that the two groups are comparable. Any differences in the male sample do not reveal a systematic pattern but rather are partially in favor of the treatment group and partially in favor of the comparison group. In the female sample, the increasing social openness of high schools seems to be slightly more pronounced in the comparison group. However, differences are small and the values of most variables are comparable between groups and have developed similarly over time. Thus, the descriptive picture does not indicate that a selection bias is likely to exist. Nevertheless, the few small differences support the consideration of sociodemographic and family background characteristics in the estimation of treatment effects.

\footnotetext{
${ }^{13} \mathrm{An}$ increase in admission grades can be observed in a few subjects. However, this development should not be a problem because in some cases, admission grades also increased in other years that are not related to the double cohorts (e.g., from 2009 to 2010). Furthermore, not only admission grades but also the average grades of high school graduation can vary slightly across years.
} 
Table 2: Means of Background Characteristics of Students

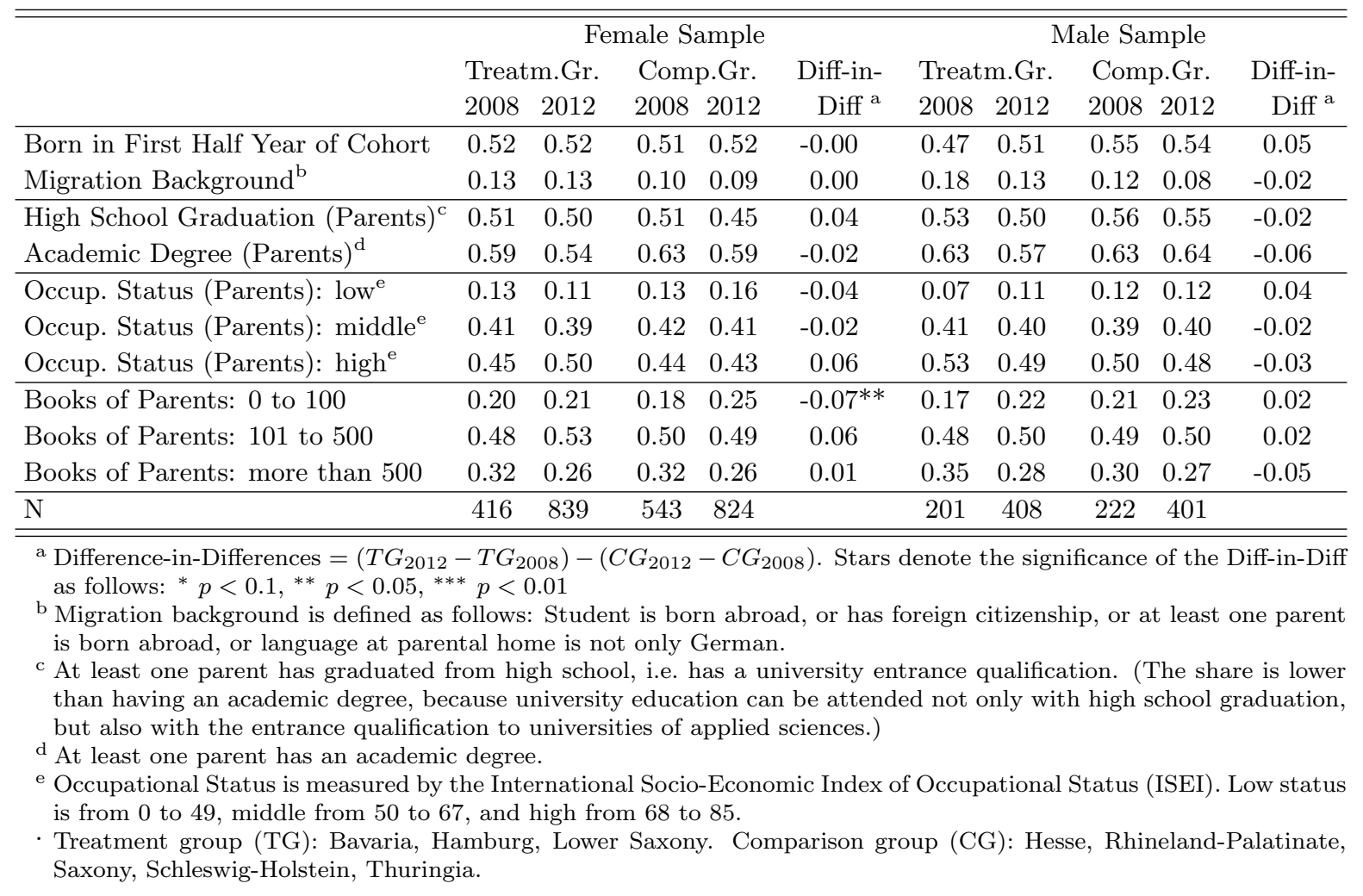

A description of the outcome variables is shown in Table 3 . Until 2008, approximately $75 \%$ of females were enrolled in postsecondary education six months after high school graduation. This share declined to nearly $60 \%$ in the treatment group in 2012, whereas it remained constant in the comparison group. The decline was driven mainly by reduced university enrollment in the first year after graduation and a notable increase in the share of students engaging in voluntary service or spending a year abroad. In the case of male students, the share of those enrolled in postsecondary education increased from $20 \%$ in 2002 to $50 \%$ in 2008 and to more than $70 \%$ in 2012. The main reason for this increase was the elimination of compulsory military and civilian service in 2011. The share of male students performing activities other than postsecondary education decreased from over $50 \%$ to approximately $25 \%$.

The enrollment shares in postsecondary education increased for both genders to between 95\% and $99 \%$ when firmly planned enrollment (which in nearly all cases takes place one year after graduation, e.g., after having completed voluntary service) is included. Altogether, approximately $80 \%$ of female students start or firmly plan to start university education and 15 to $20 \%$ choose vocational education. Male students are slightly more likely than females to enroll in university and thus show slightly lower participation in vocational education. Almost no differences exist between the treatment and comparison groups with respect to the subject of the started or firmly planned university education.

As noted above in section 3.1, the DZHW data are subject to panel attrition, which is more pronounced for males than for females. Due to this, the female sample in the DZHW data (second wave) is about twice as large as the male sample. This is due to two facts: First, 
Table 3: Means of Postsecondary Education Decisions of Students

\begin{tabular}{|c|c|c|c|c|c|c|c|c|c|c|c|c|c|}
\hline & & \multicolumn{6}{|c|}{ Female Sample } & \multicolumn{6}{|c|}{ Male Sample } \\
\hline & & 2002 & 2004 & 2006 & 2008 & 2010 & 2012 & 2002 & 2004 & 2006 & 2008 & 2010 & 2012 \\
\hline \multicolumn{14}{|c|}{ First Postsecondary Education ${ }^{a}$} \\
\hline \multirow[t]{2}{*}{ Postsecondary Ed. started } & TG & 0.76 & 0.70 & 0.73 & 0.75 & 0.81 & 0.62 & 0.20 & 0.35 & 0.45 & 0.50 & 0.55 & 0.74 \\
\hline & CG & 0.79 & 0.72 & 0.74 & 0.75 & 0.74 & 0.73 & 0.19 & 0.27 & 0.40 & 0.46 & 0.46 & 0.73 \\
\hline \multirow[t]{2}{*}{ Postsecond. Ed. started/pl. } & TG & 0.97 & 0.97 & 0.96 & 0.99 & 0.97 & 0.97 & 0.95 & 0.98 & 0.95 & 0.97 & 0.95 & 0.97 \\
\hline & $\mathrm{CG}$ & 0.98 & 0.98 & 0.97 & 0.98 & 0.97 & 0.97 & 0.95 & 0.96 & 0.96 & 0.96 & 0.97 & 0.96 \\
\hline \multirow[t]{2}{*}{ University Ed. started } & TG & 0.63 & 0.55 & 0.59 & 0.59 & 0.69 & 0.50 & 0.18 & 0.28 & 0.41 & 0.43 & 0.47 & 0.62 \\
\hline & CG & 0.58 & 0.56 & 0.54 & 0.61 & 0.60 & 0.58 & 0.17 & 0.25 & 0.36 & 0.41 & 0.42 & 0.62 \\
\hline \multirow[t]{2}{*}{ University Ed. started/pl. } & TG & 0.81 & 0.77 & 0.78 & 0.79 & 0.82 & 0.80 & 0.85 & 0.88 & 0.89 & 0.90 & 0.85 & 0.82 \\
\hline & CG & 0.73 & 0.77 & 0.74 & 0.81 & 0.80 & 0.78 & 0.84 & 0.86 & 0.86 & 0.88 & 0.87 & 0.84 \\
\hline \multirow[t]{2}{*}{ Vocational Ed. started } & TG & 0.13 & 0.15 & 0.14 & 0.16 & 0.12 & 0.12 & 0.02 & 0.07 & 0.04 & 0.07 & 0.08 & 0.12 \\
\hline & CG & 0.21 & 0.16 & 0.20 & 0.14 & 0.14 & 0.15 & 0.02 & 0.02 & 0.04 & 0.05 & 0.04 & 0.11 \\
\hline \multirow[t]{2}{*}{ Vocational Ed. started/pl. } & TG & 0.16 & 0.20 & 0.18 & 0.20 & 0.15 & 0.17 & 0.10 & 0.10 & 0.06 & 0.07 & 0.10 & 0.15 \\
\hline & $\mathrm{CG}$ & 0.25 & 0.21 & 0.23 & 0.17 & 0.17 & 0.19 & 0.11 & 0.10 & 0.10 & 0.08 & 0.10 & 0.12 \\
\hline \multicolumn{14}{|c|}{ Other Activities in the Year after High School Graduation ${ }^{b}$} \\
\hline \multirow[t]{2}{*}{ Military/Civilian Service } & TG & 0.00 & 0.00 & 0.00 & 0.00 & 0.00 & 0.00 & 0.74 & 0.56 & 0.46 & 0.41 & 0.35 & 0.01 \\
\hline & CG & 0.00 & 0.00 & 0.00 & 0.00 & 0.00 & 0.00 & 0.77 & 0.66 & 0.48 & 0.41 & 0.40 & 0.01 \\
\hline \multirow[t]{2}{*}{ Internship / Temp. Work } & TG & 0.13 & 0.18 & 0.13 & 0.12 & 0.09 & 0.14 & 0.03 & 0.05 & 0.02 & 0.04 & 0.03 & 0.11 \\
\hline & CG & 0.08 & 0.12 & 0.09 & 0.09 & 0.07 & 0.07 & 0.01 & 0.03 & 0.05 & 0.05 & 0.04 & 0.07 \\
\hline \multirow[t]{2}{*}{ Voluntary S. / Stay Abr. } & TG & 0.09 & 0.11 & 0.11 & 0.11 & 0.08 & 0.22 & 0.01 & 0.04 & 0.04 & 0.04 & 0.07 & 0.13 \\
\hline & CG & 0.11 & 0.14 & 0.20 & 0.14 & 0.14 & 0.15 & 0.01 & 0.02 & 0.06 & 0.08 & 0.07 & 0.17 \\
\hline \multirow[t]{2}{*}{ Sum of Other Activities } & TG & 0.22 & 0.29 & 0.24 & 0.23 & 0.17 & 0.36 & 0.78 & 0.65 & 0.52 & 0.49 & 0.45 & 0.25 \\
\hline & CG & 0.19 & 0.26 & 0.29 & 0.23 & 0.21 & 0.22 & 0.79 & 0.71 & 0.59 & 0.54 & 0.51 & 0.25 \\
\hline \multicolumn{14}{|c|}{ Subject of started/planned University Education ${ }^{c}$} \\
\hline \multirow[t]{2}{*}{ STEM (narrow def.) } & TG & 0.15 & 0.13 & 0.18 & 0.18 & 0.17 & 0.20 & 0.36 & 0.44 & 0.53 & 0.46 & 0.47 & 0.44 \\
\hline & CG & 0.12 & 0.13 & 0.12 & 0.19 & 0.17 & 0.16 & 0.38 & 0.50 & 0.44 & 0.52 & 0.49 & 0.44 \\
\hline \multirow[t]{2}{*}{ STEM (broad def.) } & TG & 0.23 & 0.25 & 0.26 & 0.28 & 0.27 & 0.27 & 0.42 & 0.50 & 0.60 & 0.52 & 0.53 & 0.46 \\
\hline & CG & 0.20 & 0.22 & 0.22 & 0.28 & 0.27 & 0.26 & 0.42 & 0.50 & 0.51 & 0.59 & 0.52 & 0.49 \\
\hline \multirow[t]{2}{*}{$\mathrm{N}$} & TG & 703 & 365 & 401 & 416 & 690 & 839 & 376 & 197 & 212 & 201 & 365 & 408 \\
\hline & $\mathrm{CG}$ & 1216 & 545 & 483 & 543 & 600 & 824 & 491 & 235 & 196 & 222 & 205 & 401 \\
\hline \multicolumn{14}{|c|}{$\begin{array}{l}\text { a Share of high school graduates being enrolled (or having decided to enroll in near future) in university or vocational } \\
\text { education half a year after school graduation. } \\
\text { b Share of high school graduates participating in different activities half a year after school graduation. } \\
\text { c Share of high school graduates being enrolled or planning to enroll in a specific university subject. } \\
\text {. Treatment group (TG): Bavaria, Hamburg, Lower Saxony. Comparison group (CG): Hesse, Rhineland-Palatinate, } \\
\text { Saxony, Schleswig-Holstein. Thuringia. }\end{array}$} \\
\hline
\end{tabular}

more female than male students graduate from high school (according to the Federal Statistical Office (various years a) the gender ratio of German high school graduates was 57:43 in 2008 and 55:45 in 2012, with only little variation across states). Secondly, female students are generally more likely to participate in a survey than males (see, e.g., Burkam and Lee, 1998; Porter and Whitcomb, 2005).

Importantly, for the analysis at hand, the relative shares of both genders do not affect the empirical results since we conduct a gender-separated analysis. In addition, there are no (strong) indications of a potential bias across genders due to gender-specific panel attrition. Table A.1 in the appendix compares the means of selected variables between waves by genders and by treatment and comparison group. In the majority of cases, the differences in means between waves are negligible. If at all, a slightly positive selection may be indicated by the differences in grades and study plans (university education planned). If the small differences would have an effect, our estimated effects below would represent lower bound estimates of the true treatment 
effects.

\section{Estimation Results}

\subsection{Reform Effects on Postsecondary Education Decisions}

The estimation results of our main treatment group (pre-/post-reform years 2008/2012, treatment group 1) are presented in columns (1) and (4) of Table 4. Only the reform effects are reported, but all other explanatory variables are also considered in the estimations (results not presented) ${ }^{14}$ Effects on university and vocational education are shown with respect to actual enrollment (i.e., actually started six months after graduation) as well as actual and firmly planned enrollment (i.e., actually started six months after graduation or firmly plan to start within the next year). The results indicate gender-specific effects. The reform significantly reduced females' enrollment in university education in the first year after high school graduation by approximately 10 percentage points. However, if enrollment plans are included, this effect disappears. There is no significant effect on females' enrollment in vocational education. For male students, enrollment decisions (in either university or vocational education) are not affected. These results do not imply that no enrollment effects exist beyond the first year. In this study, enrollment plans are limited to initial postsecondary education decisions; later modifications or participation in additional courses of education (e.g., attending university after vocational education, or vice versa) are not considered. Therefore, the probability of starting university or vocational education may be affected by the reform in the long-term.

In addition to starting university or vocational education, a portion of students use the year after high school graduation to engage in other activities. The most common activities are performing military or civilian service (which was obligatory for many males until 2011), spending a year volunteering with social, ecological or cultural institutions, spending a year abroad (e.g., to work and travel or as an au pair), engaging in an internship and working temporarily. Military and civilian service is not affected by the reform because it is controlled by the official authorities. For female high school graduates, the probability of taking an internship or temporary work increased slightly by 6 percentage points and the probability of spending a year abroad or performing voluntary service increased by approximately 10 percentage points. For males, again no effect is observed. Although all coefficients are in the same direction as those of the females, they are rather small in size.

Finally, students' choices of fields of study for actual or firmly planned university education are largely unchanged by the reform. The effects on almost all subjects are small and statistically insignificant (regardless of whether we consider all high school graduates or only those graduates who started or firmly plan to start university education). Exceptions include the probability of male students studying education sciences (particularly teaching professions), which is slightly reduced, and the probability of females studying engineering, which is slightly increased (results not shown). However, the coefficients of natural sciences and medical sciences

\footnotetext{
${ }^{14}$ Results from estimations without additional control variables are shown in Table A.7 in the appendix; they are very similar to the results presented in Table 4
} 
further checked for varying definitions of treatment group 2. The obtained patterns are robust regardless of whether all four states are added, only the three small states (Berlin, Brandenburg, Bremen) are added or only the large state of Baden-Wuerttemberg is added (results not shown).

Secondly, we use 2006 as the pre-reform year (instead of 2008) and define MecklenburgWestern Pomerania and Saxony-Anhalt as treatment states (treatment group 3). This treatment group definition is intended to reveal whether the findings reflect only temporary effects of the reform rather than permanent effects. The results in columns (3) and (6) confirm the findings from the previous analyses for both genders. For that reason, they provide evidence that the effects of the reform are permanent. In the male sample, the coefficients become even larger. Only two differences occur: First, the probability of females engaging in internships or working temporarily is no longer increased. However, the effect of the reform on voluntary service or staying abroad is larger, meaning that the sum of both activities is the same as before. The second difference concerns the choice of university subject. The coefficients in the female sample change their direction (but remain statistically insignificant), and a large negative effect on males' enrollment in STEM subjects is observed. However, the latter result should be interpreted with caution because the share of male students in the treatment group who chose a STEM subject was unusually high in 2006 compared to the other years. The results regarding subject choice based on the more common pre-reform year of 2008 provide a more reliable and resilient picture of the reform effects.

\subsection{Effect Heterogeneity Across Federal States}

Although the implementation of the reform was in principle similar across federal states, some differences exist. To investigate potential effect heterogeneity across states and to rule out that reform effects are driven by a specific state, we estimate regressions excluding single states stepby-step from the treatment group. In the case of treatment group 1, only two treatment states (instead of three) are considered at a time.

The results presented in Table 5 show a high persistence of the reform effects across specifications. Some small effect heterogeneity across states can be observed. The effect on females' enrollment in university education decreases slightly if Lower Saxony is excluded from the treatment group, but the difference in size is not large. However, the effect on performing voluntary service or staying abroad becomes statistically insignificant (although the coefficient is still positive), indicating that the effect is driven by Lower Saxony. This conclusion is further reflected in the larger coefficient obtained from the sample without Bavaria. Moreover, if Bavaria is omitted, female students are less likely to start not only university education in the first year after graduation but also vocational education. Overall, the main effect of the reform - that is, delayed university enrollment of female students - exists in all analyzed states. With respect to the other activities (vocational education, voluntary service, and staying abroad), slight effect heterogeneity is observed across states. 
Table 5: Difference-in-Differences Estimates of Reform Effects: Estimations Without One Treatment State (Treatment Group 1, Marginal Effects)

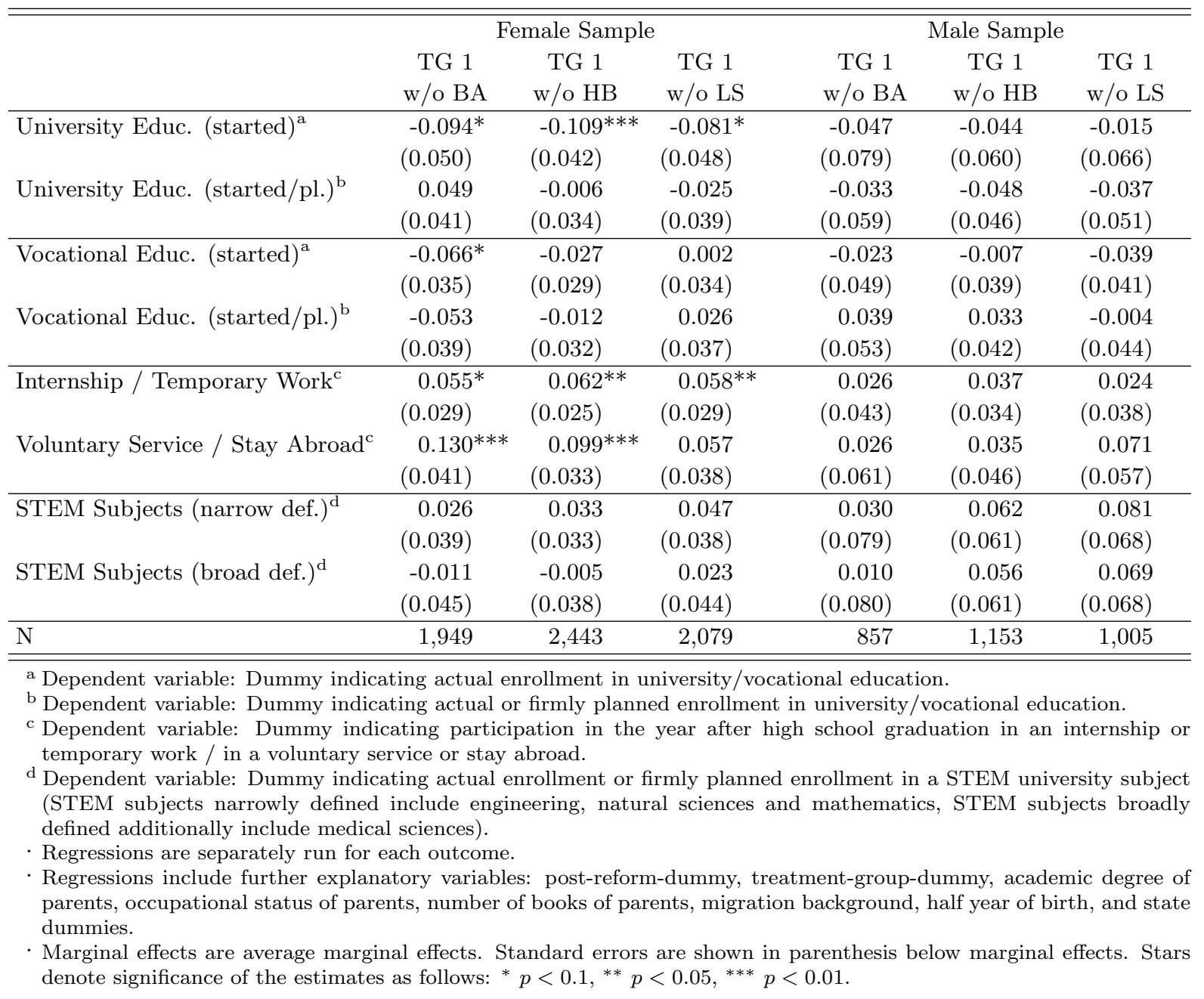

\subsection{Effect Heterogeneity Based on Students' Family Backgrounds}

The findings obtained so far represent average effects across all high school graduates. However, students with different socio-economic backgrounds may be affected differently by the reform, and this kind of effect heterogeneity will be analyzed in the following. One of the main determinants of postsecondary education decisions is the educational background of the student's family. We therefore divided the sample into two groups: students coming from a family in which at least one parent has an academic degree and students with a non-academic family background.

The results obtained from the separate estimations (Table 6) show considerably different reactions to the reform by the two groups of students. Although no effect was found for male students on average (see above), those coming from non-academic families are significantly less likely to start university education. This effect holds not only for the first year after high school graduation but also beyond that year. In contrast, male students with an academic background are not affected.

In the case of female students, the picture is a bit more heterogeneous. Reduced university 
Table 6: Difference-in-Differences Estimates of Reform Effects: Separate Estimations for Students with Academic and Non-Academic Family Background (Treatment Group 1, Marginal Effects)

\begin{tabular}{|c|c|c|c|c|}
\hline & \multicolumn{2}{|c|}{ Female Sample } & \multicolumn{2}{|c|}{ Male Sample } \\
\hline & $\begin{array}{c}\text { academic } \\
\text { family }^{\mathrm{e}}\end{array}$ & $\begin{array}{c}\text { non-academic } \\
\text { family }^{\mathrm{e}}\end{array}$ & $\begin{array}{l}\text { academic } \\
\text { family }^{\mathrm{e}}\end{array}$ & $\begin{array}{c}\text { non-academic } \\
\text { family }^{\mathrm{e}}\end{array}$ \\
\hline \multirow[t]{2}{*}{ University Education (started) ${ }^{\mathrm{a}}$} & -0.066 & $-0.142^{* *}$ & 0.016 & $-0.166^{*}$ \\
\hline & $(0.053)$ & $(0.064)$ & $(0.076)$ & $(0.096)$ \\
\hline \multirow[t]{2}{*}{ University Education (started/planned) ${ }^{\mathrm{b}}$} & $0.066^{*}$ & -0.092 & 0.011 & $-0.135^{*}$ \\
\hline & $(0.040)$ & $(0.057)$ & $(0.054)$ & $(0.081)$ \\
\hline \multirow[t]{2}{*}{ Vocational Education (started) ${ }^{\mathrm{a}}$} & $-0.060^{*}$ & 0.028 & -0.070 & 0.049 \\
\hline & $(0.033)$ & $(0.051)$ & $(0.049)$ & $(0.069)$ \\
\hline \multirow[t]{2}{*}{ Vocational Education (started/planned) ${ }^{\mathrm{b}}$} & $-0.075^{* *}$ & 0.085 & -0.033 & 0.114 \\
\hline & $(0.036)$ & $(0.055)$ & $(0.048)$ & $(0.077)$ \\
\hline \multirow[t]{2}{*}{ Internship or Temporary Work ${ }^{c}$} & 0.037 & $0.102^{* * *}$ & 0.021 & 0.066 \\
\hline & $(0.034)$ & $(0.039)$ & $(0.046)$ & $(0.052)$ \\
\hline \multirow[t]{2}{*}{ Voluntary Service or Stay Abroad ${ }^{\mathrm{c}}$} & $0.127^{* * *}$ & 0.032 & 0.020 & 0.119 \\
\hline & $(0.044)$ & $(0.050)$ & $(0.058)$ & $(0.082)$ \\
\hline \multirow[t]{2}{*}{ STEM Subjects (narrow definition) ${ }^{\mathrm{d}}$} & 0.069 & 0.002 & 0.072 & 0.043 \\
\hline & $(0.043)$ & $(0.049)$ & $(0.076)$ & $(0.098)$ \\
\hline \multirow[t]{2}{*}{ STEM Subjects (broad definition) ${ }^{\mathrm{d}}$} & 0.036 & -0.027 & 0.080 & -0.000 \\
\hline & $(0.050)$ & $(0.055)$ & $(0.076)$ & $(0.098)$ \\
\hline $\mathrm{N}$ & 1,490 & 1,076 & 737 & 464 \\
\hline \multicolumn{5}{|c|}{$\begin{array}{l}\text { a Dependent variable: Dummy indicating actual enrollment in university/vocational education. } \\
\text { b Dependent variable: Dummy indicating actual or firmly planned enrollment in university/vocational education. } \\
\text { c Dependent variable: Dummy indicating participation in the year after high school graduation in an internship or } \\
\text { temporary work / in a voluntary service or stay abroad. } \\
\text { d Dependent variable: Dummy indicating actual enrollment or firmly planned enrollment in a STEM university } \\
\text { subject (STEM subjects narrowly defined include engineering, natural sciences and mathematics, STEM subjects } \\
\text { broadly defined additionally include medical sciences). } \\
\text { e A student is defined to come from an academic family if at least one parent has an academic degree. } \\
\text { - Regressions are separately run for each outcome. } \\
\text { Regressions include further explanatory variables: post-reform-dummy, treatment-group-dummy, occupational } \\
\text { status of parents, number of books of parents, migration background, half year of birth, and state dummies. } \\
\text { Marginal effects are average marginal effects. Standard errors are shown in parenthesis below marginal effects. } \\
\text { Stars denote significance of the estimates as follows: }{ }^{*} p<0.1,{ }^{* *} p<0.05,{ }^{* * *} p<0.01 \text {. }\end{array}$} \\
\hline
\end{tabular}

enrollment in the first year after high school graduation is also driven by students with a non-academic family background. This reduction is primarily due to an increased probability of taking an internship or temporary work. In contrast, female students with an academic family background are less likely by approximately 6 to 8 percentage points to participate in vocational education (with respect to both actual and planned enrollment). In addition, these female students are more likely by 12 percentage points to perform voluntary service or to spend a year abroad. This leads to a statistically insignificant decrease in university enrollment in the first year after high school graduation, while enrollment increases slightly in the second year.

Overall, students coming from non-academic families seem to be much more negatively affected by the reform than students with an academic family background. For the latter, no effect is observed in the male sample, whereas the delayed but higher university enrollment of these females represents a mixed finding. 


\subsection{Robustness Checks}

\section{Estimations Using 2006 as the Pre-Reform-Year}

We explained in section 3.2 that 2008 can be assumed to be a more suitable pre-reform year than 2006. However, to determine whether the choice of the pre-reform year has an influence on the results, we conducted estimations using 2006 as the pre-reform period. The corresponding results in Table A.8 in the appendix are similar to those obtained using 2008 as the prereform year. The effect on university enrollment becomes even larger, whereas the effects on internships/temporary work and voluntary service/staying abroad decrease slightly but remain statistically significant. Moreover, additional effects occur, but in most cases they hold for only one of the two treatment groups. Therefore - and because they do not occur in the main treatment group - these slight deviations are not considered further.

\section{Estimations Without One Comparison State}

To rule out that the effects are driven by a specific state in the comparison group, we adapt the comparison groups in the estimation by excluding single states step-by-step from the model (which is analogous to the estimations presented in section 4.3). As shown in Table A.9 in the appendix, almost all effects remain constant. There is only one exception: the reduced enrollment of female students in university education in the first year after high school graduation becomes insignificant if Saxony is excluded from the comparison group. However, the effect is close to the 10\%-level of statistical significance ( $p$-value of 0.13 ), and if Hamburg is also excluded from the treatment group (so that only Bavaria and Lower Saxony represent the treatment states), the effect becomes significant again.

\section{Placebo Difference-in-Differences Estimation}

A common sensitivity check in difference-in-differences analyses is to perform placebo tests using observations not affected by the reform as if they were the treatment group. First, the West German states from the comparison group (Hesse, Rhineland-Palatinate, Schleswig-Holstein) are used as the placebo treatment group and compared to the East German states in the comparison group (Saxony, Thuringia). Second, we use the original treatment and comparison groups but define 2006 and 2008 as placebo pre- and post-reform years. Third, students from the four states that had a double cohort of graduates in 2012 (Baden-Wuerttemberg, Berlin, Brandenburg, Bremen) are used as the placebo treatment group (but only the students graduating after 13 years of schooling) and compared to the original comparison group. If the findings mentioned above represent causal effects of the reform, they should disappear in the placebo tests. This is the case, as the coefficients of all previously identified reform effects become small and statistically insignificant (Table A.10 in the appendix).

It must be mentioned that for enrollment in vocational education, the placebo tests do not perfectly rule out treatment effects. Placebo test 1 reveals slightly opposing trends between the West and East German comparison states. The significant coefficients in placebo test 2 reflect 
the problem mentioned in section 3.2 , i.e., that the 2006 values of some variables (vocational education and enrollment in STEM subjects) are atypically high or low in some states. This issue was one reason for using 2008 as the pre-reform year instead of 2006, a decision that is supported by these placebo tests. Finally, the lack of significant effects in placebo test 3 (i.e., for students with 13 years of schooling in the 2012 double cohorts) supports the assumption that the double cohorts did not intensify the competition for apprenticeships and study places.

\section{Possible Confounding Effects of Other Reforms}

As discussed in section 3.3 , a few other education reforms have been introduced during the analyzed period. Because these reforms could possibly confound the effects of the shortened school duration, we have conducted additional robustness checks. First, the states that changed their high school curriculum between 2008 and 2012 are excluded from the analysis (Bavaria, Hamburg, Saxony, Schleswig-Holstein, Thuringia; see Table A.5 in the appendix). As shown in column (1) of Table A.11 in the appendix, the reform effects remain stable. Only the effect on the probability of taking an internship or working temporarily becomes slightly insignificant for females but remains nearly constant in size. In contrast, a significant effect on vocational education occurs, which nonetheless should not be overrated, because only one treatment state and two comparison states are compared in this case.

Second, only the state of Bavaria is used as the treatment group. In contrast to Lower Saxony and Hamburg, it is not possible in Bavaria to obtain the university admittance qualification at comprehensive schools (and almost no comprehensive schools exist in this state). In addition, tracking was not changed and the reform was implemented very quickly. Although official statistics do not indicate a movement of students from high schools (Gymnasium) to comprehensive schools after reform introduction (as mentioned in section 3.3), this check can be seen as an additional test for a potential selection bias. The results in column (2) of Table A.11 largely confirm the original findings. Although the effect on the probability of female students participating in voluntary service or staying abroad is no longer significant, this change may not point to a confounding influence but could also represent a state-specific effect, namely that engaging in voluntary service or spending a year abroad is not chosen in Bavaria as often as in Lower Saxony, as previously indicated in section 4.3 .

Furthermore, one might think that the introduction of university tuition fees in certain federal states could have confounded the results. However, such a confounding effect is unlikely because no evidence was found by Helbig et al. (2012) and Bruckmeier and Wigger (2014) that tuition fees influence enrollment at university. Moreover, some states did not introduce tuition fees at all, and in other states, the introduction had taken place before 2008 and remained valid in 2012. From the states in our main treatment group, only students in Hamburg were required to pay tuition fees in 2008, and these fees were abolished or were going to be abolished in 2012. ${ }^{15}$

\footnotetext{
${ }^{15}$ In Hamburg, tuition fees were introduced in 2007, but their elimination was resolved in 2011 and implemented in 2013. In Table A.5 in the appendix, Hesse is also indicated as having fees in 2008 but not in 2012. However, fees were eliminated in the summer of 2008, which means that high school graduates in the 2008 cohort were not affected by the fees.
} 
At any time during our observation period, students had sufficient possibilities to study in a state without tuition fees. In addition, even if tuition fees reduced university attendance, the negative effect of the reform on university enrollment would represent a lower bound estimate. However, excluding the state of Hamburg from the treatment group does not change the results (see Table 5 above).

Finally, the original estimations are conducted with two additional control variables; one indicates whether a student in a given state and year graduated from high school under the changed curriculum, and the other indicates whether a student was expecting university tuition fees in his home state. The results in column (3) of Table A.11 are very similar to the main findings discussed above.

Altogether, the various robustness checks largely confirm the obtained picture of the effects on postsecondary education decisions. Although some coefficients lose their statistical significance in a few cases, the increased tendency of female students to delay university enrollment and engage in voluntary service or spend a year abroad can be found in all robustness checks.

\subsection{Effect Channels}

We have shown that the reform has led to a delayed entry into postsecondary education combined with higher participation in other activities following graduation. Several explanations are conceivable for these findings (see section 2.2 above). Due to the shorter school duration and the younger graduation age, for example, treated students might not feel mature enough for university education or could have a higher degree of insecurity about their choice of postsecondary education. It could also be the case that the higher learning intensity experienced at school has changed their motivation or preferences. In addition to these demand-side explanations, supply-side factors (e.g., a limited number of study places) could also play a role.

To directly test the potential effect channels, we use additional information in the data on a number of aspects that characterize the decision-making process regarding postsecondary education. These aspects include, besides others, certain difficulties related to the decision (e.g., a lack of information, uncertainty about one's own interests, difficulty assessing the required skills) and reasons for delayed entry into postsecondary education (e.g., admission restrictions, the desire to take a break, indecisiveness about one's future career). We estimate the reform effects on these outcomes (using the same methodological approach as above). The estimation results (Table 7 ) show that the reform effects for female students cannot be explained by a lower inclination to start university education, increased difficulty choosing postsecondary education, or a lack of information about postsecondary education opportunities. Some coefficient estimates even point in the opposite direction. Although a negative effect on planned university education occurs in the male sample, it does not lead to lower actual enrollment, as seen above.

However, re-estimating the effect channels with consideration of the role of family background (as done in section 4.4) reveals that the reform has increased certain decision difficulties of students from non-academic families (see Table A.12 in the appendix). In particular, the reform has increased the degree of uncertainty about own abilities among female students from 
non-academic families. For male students with non-academic family backgrounds, the difficulty of managing the numerous available opportunities and the perception of unsatisfactory preparation by the high school have become more likely. These findings represent an appropriate and plausible explanation for the effects identified in section 4.4. They once again show that the reform had a detrimental impact on students with non-academic family backgrounds. In contrast, students with academic backgrounds are not more likely to report difficulties.

Compared to these channels, the question of why students have delayed entry into postsecondary education provides interesting insights. Note that the corresponding variables include all students in the sample, not only those who delayed entry into postsecondary education, and that students could select more than one reason in the questionnaire (the reasons are not mutually exclusive). The probability that entry is delayed due to unsuccessful applications for vocational education or restricted access to the desired university education is slightly increased. At first glance, this result may be interpreted as supporting the concern that the reform has restricted university access more than average in the first years after its introduction. However, this conclusion contradicts the evidence presented in section 3.3 (in particular, the non-intensification of admission grades). Moreover, the coefficient should increase in treatment group 2 (which includes the double cohorts of 2012) and also in the male sample if the introduction of the reform intensified the competition for study places. This is obviously not the case. It should be noted that the outcome variable does not indicate an increase in unsuccessful applications per se but rather an increase in the share of students that have delayed entry due to unsuccessful applications (and did not start a different course of postsecondary education after rejection). Finally, the observed increase disappears in treatment group 3 (although university enrollment is still delayed to the same extent), which means that this reason is not relevant in the long run. Thus, although restricted university access might be slightly increased, this cannot be the main reason for the reform leading to delayed university enrollment.

The second reason for delayed enrollment, which is that students had to fulfill additional requirements before starting their intended course of postsecondary education (e.g., completing an internship), occurs slightly more often after the introduction of the reform. This increase is surprising because the reform did not change the level of qualification. However, because only certain university subjects (e.g., social sciences, engineering) require the completion of an internship before commencement of study, even small changes in the pattern of university subject choice could have caused the effect.

The desire to take a break before continuing one's educational career and the desire to engage in voluntary service or to spend a year abroad are more important reasons for delayed entry into postsecondary education. Both reasons increased as a result of the reform by approximately 8 percentage points. In 2012, approximately 20 percent of students in the treatment group state that at least one of these reasons applies to them, whereas only 6 to 9 percent of them say that admission restrictions or additional requirements are the reason for the delay. Furthermore, engaging in voluntary service or staying abroad is the dominant reason for delay in treatment group 3, i.e., in the long-term. Almost all reasons apply equally to students regardless of whether they come from academic or non-academic families (see Table A.12 in the appendix). Only the 
Table 7: Difference-in-Differences Estimates of Effect Channels (Marginal Effects)

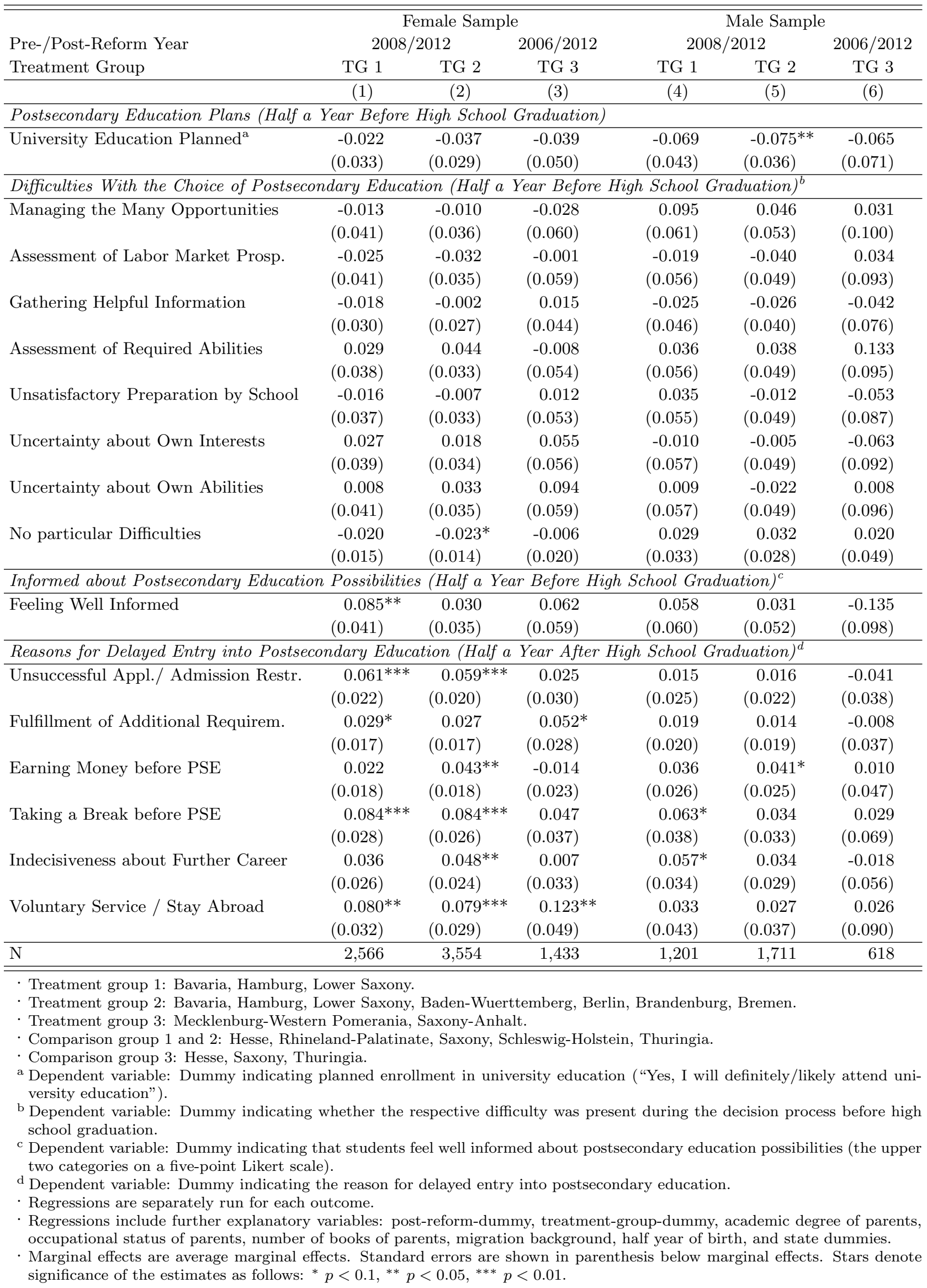


effect on the desire to take a break is slightly larger in the non-academic sample (10\% vs. $7 \%$ ), while delays due to voluntary service are more pronounced for students with academic family backgrounds ( $9 \%$ vs. $5 \%$ ).

Finally, it could be the case that the increased participation in voluntary service or staying abroad is due to the fact that the reform has reduced possibilities to spend a year abroad during high school. In the 13-year system students often used grade 11 to spend a school year abroad. If the shortened and compressed school duration made it more difficult to stay abroad during school education, it would be not surprising that students stay abroad after school graduation. Unfortunately, the information on stays abroad during school education is not available in the data on the 2008 and 2012 cohorts. However, we use a variable collected half a year before high school graduation (1st wave) that indicates whether a student has stayed abroad for at least 3 months until this point in time. It is reported in the surveys 2010 and 2015 (access to the latter is preliminary only up to now). Although this variable also contains stays abroad before high school attendance (e.g., in early childhood), it can be seen as a proxy for spending a school year abroad. Table A.13 in the appendix shows that the share of students who stayed abroad until school graduation has remained almost constant in the comparison group as well as in treatment groups 1 and 2. This could be interpreted as evidence that the reform effects cannot be explained by a decrease in students' probability to spend a year abroad during their time at high school.

Overall, we conclude that although other reasons may also play a role, the main reason for the reform effects is that students who graduate after a shorter and more compressed school duration more often want to take a break or to do something else before continuing their educational career. Nevertheless, it cannot be ruled out that performing voluntary service or spending a year abroad is an expression or indicator of other reasons, such as feeling less oriented, less mature or less motivated.

\section{Conclusion}

The importance of the duration of schooling results from the fact that time spent in school contributes not only to the development of skills but also to the discovery of tastes and talents. A major education reform in Germany reduced the duration of university preparatory schooling by one year (from 13 to 12 years). However, the requirements for final graduation remained unchanged, which means that the curriculum must be taught and learned in a shorter period of time. We have evaluated the impact of this reform on postsecondary education decisions in several German states. The evaluation is based on nationally representative data of high school graduates. The effects are identified using the different timing of reform introduction across the German states (difference-in-differences estimation).

The results show that the reform has reduced enrollment of female students in university education in the first year after high school graduation by approximately 10 to 12 percentage points. Simultaneously, the probability of engaging in a year of voluntary service or spending a year abroad has increased by up to 13 percentage points. For male students, a similar tendency 
exists but the effects are small and statistically insignificant. These effects remain stable in the vast majority of treatment group definitions and robustness checks. Furthermore, the results based on states with a double cohort in 2012 do not differ substantially from the other results, indicating that the double cohorts have not unduly restricted students' transition into postsecondary education. More importantly, the identified effects can be considered permanent because they not only apply to the first affected cohorts but also remain constant in later cohorts. The analysis of effect heterogeneity according to students' family backgrounds shows that most effects are driven by female students coming from non-academic families. Moreover, although no significant effects are observed in the male sample as a whole, a large and significant reduction in university attendance occurs when only male students with non-academic family backgrounds are considered (both in the first year after high school graduation and beyond that year). Exploring the underlying mechanisms reveals that the effects are caused mainly by an increased share of students who want to take a break after high school graduation and to spend a year, for example, volunteering or staying abroad. In addition, affected students from non-academic families experience more difficulties when choosing their postsecondary education.

Altogether, the analysis finds that considerable effects on postsecondary education decisions were caused by the reduction in school duration. Because the impacts are similar across a number of federal states, they can be considered generally valid. The results also largely confirm the findings of a previous study based on detailed data for Saxony-Anhalt (Meyer and Thomsen, 2016). However, a few differences exist that should be discussed. The first difference is that for female students, no effect on university enrollment beyond the first year or on vocational education is observed. We conclude that the reform has delayed enrollment in university education in all cases, but the reason for delay differs. In the states and years analyzed, affected students decide more frequently to engage in voluntary service or to stay abroad for one year, whereas affected students in other states or years choose vocational education instead, which normally takes approximately three years to complete. This interpretation is underlined by the investigation of effect heterogeneity and some robustness checks, which reveal that the effects on vocational education differ among states and between students with academic/non-academic family backgrounds. The second difference, finding at least a tendency of reduced or delayed university enrollment for male students which was not observed in Meyer and Thomsen (2016), may be explained by the elimination of compulsory military or civilian service in 2011. Before its elimination, compulsory service gave many male students an additional year after high school to consider their postsecondary education. After its elimination, male students are in the same position as female students in terms of their education decisions. The question of why female students are affected more than male students remains unanswered. It is possible that females have a higher affinity for voluntary service or for staying abroad than males and thus they are more likely to take a gap year after high school graduation. The final difference is related to the choice of university subject, where no effects have been identified in this paper (for the main treatment group) ${ }^{16}$ Therefore, it could be the case that the reform has an impact on subject

\footnotetext{
${ }^{16}$ As mentioned above, the lower probability of male students studying a STEM subject, which has been found in the treatment group that uses 2006 as the pre-reform year, is due to an atypically high share of students in
} 
choice only in some states, e.g., Saxony-Anhalt. Overall, the partially different findings highlight that some effects of the reduced school duration could vary by state (depending on how the reform is introduced or on student characteristics). However, the main result of delayed university enrollment in the short-term and a corresponding increase in alternative activities or courses of education can be considered generally valid.

The objective of the reform was to achieve the same quality of education within a shorter duration and therefore to allow an earlier start for students' university education and occupational careers. Because the analysis covers only those effects in the first years following high school graduation, it is difficult to say whether this objective will be achieved. For example, it cannot be ruled out that final participation and completion rates as well as the duration of university education will be affected. Nevertheless, the results so far show that the probability of delaying university enrollment by one year has increased by approximately 10 percentage points due to the reform, which in turn means that $90 \%$ of students enter postsecondary education, and subsequently the labor market, one year earlier than before the reform. From this perspective, the reform could be seen as an efficiency gain in education production, but the full potential of the reform is not achieved. It is questionable whether education policy can improve anything in this respect, because the main reason for delays is not insufficient preparation by the schools or indecisiveness about future careers but rather the desire to take a break before continuing one's educational career and to spend a year abroad or participating in voluntary service. However, it could be the case that this desire is caused by a lower degree of perceived maturity or a higher degree of insecurity about postsecondary education decisions. Finally, delayed enrollment does not necessarily represent a negative result. Spending a year abroad or volunteering can benefit students by broadening their personal horizons, giving them social and intercultural experiences, and potentially increasing the match quality of future career choices.

\section{Acknowledgements}

We would like to thank an anonymous referee for very helpful comments. The paper has benefited from discussions at the Lower Saxony Workshop in Applied Economics 2014, the RWI Research Network Conference 2014, the COMPIE Conference 2014, the Annual Congress of the European Economic Association 2015, the Annual Congress of the Verein für Socialpolitik 2015, the ZEW Summer School 2015, the Annual Congress of the International Institute of Public Finance 2016, the Research Seminar at FAU Nürnberg 2016, the Annual Congress of the Royal Economic Society 2017, and the Annual Meeting of the Society of Labor Economists 2017. We would like to thank all participants and discussants for their helpful comments. We thank the American Journal Experts for providing linguistic proof-reading. We also thank the German Centre for Higher Education Research and Science Studies (DZHW) for providing the data. Financial support from the German Research Foundation (DFG), projects TH $1499 / 2-1$ to TH $1499 / 2-3$, is gratefully acknowledged.

the treatment states choosing these subjects in 2006 compared to other years. 


\section{References}

AJzen, I. (1991): "The Theory of Planned Behavior," Organizational Behavior and Human Decision Processes, 50(2), 179-211.

Aughinbaugh, A. (2012): "The effects of high school math curriculum on college attendance: Evidence from the NLSY97," Economics of Education Review, 31(6), 861-870.

Bedard, K., And E. Dhuey (2006): "The Persistence of Early Childhood Maturity: International Evidence of Long-Run Age Effects," The Quarterly Journal of Economics, 121(4), $1437-1472$.

BeLleI, C. (2009): "Does lengthening the school day increase students' academic achievement? Results from a natural experiment in Chile," Economics of Education Review, 28(5), 629-640.

Bertrand, M., E. Duflo, and S. Mullainathan (2004): "How Much Should We Trust Differences-in-Differences Estimates?," Quarterly Journal of Economics, 119(1), 249-275.

Bruckmeier, K., AND B. U. Wigger (2014): "The effects of tuition fees on transition from high school to university in Germany," Economics of Education Review, 41, 14-23.

Buchmann, C., T. A. DiPrete, and A. McDaniel (2008): "Gender Inequalities in Education," Annual Review of Sociology, 34, 319-337.

Burkam, D. T., And V. E. LeE (1998): "Effects of Monotone and Nonmonotone Attrition on Parameter Estimates in Regression Models with Educational Data: Demographic Effects on Achievement, Aspirations, and Attitudes," Journal of Human Resources, 33(2), 555-574.

Büttner, B., and S. L. Thomsen (2015): "Are We Spending Too Many Years in School? Causal Evidence of the Impact of Shortening Secondary School Duration," German Economic Review, 16(1), 65-86.

Crawford, C., L. Dearden, and C. Meghir (2010): "When you are born matters: the impact of date of birth on educational outcomes in England," DoQSS Working Paper 10-09.

Dahmann, S., And S. Anger (2014): "The Impact of Education on Personality: Evidence from a German High School Reform," IZA Discussion Paper 8139.

Falch, T., O. H. Nyhus, and B. Strom (2014): "Causal effects of mathematics," Labour Economics, 31, 174-187.

Federal Statistical Office (various yearsa): "Allgemeinbildende Schulen, Fachserie 11, Reihe 1," Statistisches Bundesamt, Wiesbaden, several years, 1998-2014.

- (various years b): "Berufliche Schulen, Fachserie 11, Reihe 2," Statistisches Bundesamt, Wiesbaden, several years, 2008-2014.

(various years c): "Studierende an Hochschulen, Fachserie 11, Reihe 4.1," Statistisches Bundesamt, Wiesbaden, several years, 2008-2012. 
Fredriksson, P., And B. Öckert (2014): "Life-cycle Effects of Age at School Start," The Economic Journal, 124(579), 977-1004.

Ganzeboom, H. B. G., P. M. De Graaf, and D. J. Treiman (1992): "A Standard International Socio-Economic Index of Occupational Status," Social Science Research, 21(1), $1-56$.

Hübner, N., W. Wagner, J. Kramer, B. Nagengast, and U. Trautwein (2017): "Die G8-Reform in Baden-Württemberg: Kompetenzen, Wohlbefinden und Freizeitverhalten vor und nach der Reform," Zeitschrift für Erziehungswissenschaft, online first, doi:10.1007/s11618-017-0737-3.

Helbig, M., T. Baier, And A. Kroth (2012): "Die Auswirkung von Studiengebühren auf die Studierneigung in Deutschland. Evidenz aus einem natürlichen Experiment aus Basis der HIS-Studienberechtigtenbefragung," Zeitschrift für Soziologie, 41(3), 227-246.

Huebener, M., and J. Marcus (2017): "Compressing instruction time into fewer years of schooling and the impact on student performance," Economics of Education Review, 58, 1-14.

KüHN, S. M. (2014): "Sind 12 Schuljahre ausreichend für den Zugang zur Hochschule? Der doppelte Abiturjahrgang aus empirischer Perspektive," Beiträge zur Hochschulforschung, 36(3), $8-33$.

Krashinsky, H. (2014): "How Would One Extra Year of High School Affect Academic Performance in University? Evidence from an Educational Policy Change," Canadian Journal of Economics, 47(1), 70-97.

LÖrz, M., H. QuAst, AND A. Woisch (2012): "Erwartungen, Entscheidungen und Bildungswege. Studienberechtigte 2010 ein halbes Jahr nach Schulabgang," Forum Hochschule 5/2012, HIS, Hannover.

Malamud, O. (2011): "Discovering One's Talent: Learning from Academic Specialization," Industrial and Labor Relations Review, 64(2), 375-405.

Marcotte, D. E. (2007): "Schooling and test scores: A mother-natural experiment," Economics of Education Review, 26(5), 629-640.

Marcus, J., And V. Zambre (2016): "The Effect of Increasing Education Efficiency on University Enrollment: Evidence from Administrative Data and an Unusual Schooling Reform in Germany," DIW Discussion Paper 1613.

MeYer, B. D. (1995): "Natural and Quasi-Experiments in Economics," Journal of Business \& Economic Statistics, 13(2), 151-161.

Meyer, T., And S. L. Thomsen (2015): "Schneller fertig, aber weniger Freizeit? - Eine Evaluation der Wirkungen der verkürzten Gymnasialschulzeit auf die außerschulischen Aktivitäten der Schülerinnen und Schüler," Schmollers Jahrbuch, 135(3), 249-277. 
(2016): "How Important is Secondary School Duration for Postsecondary Education Decisions? Evidence from a Natural Experiment," Journal of Human Capital, 10(1), 67-108.

- (2017): "The Role of High-School Duration for University Students' Motivation, Abilities and Achievements," Education Economics, online first, http://dx.doi.org/10.1080/09645292.2017.1351525.

OECD (2010): Learning for Jobs, OECD Reviews of Vocational Education and Training. OECD Publishing, Paris.

Porter, S. R., And M. E. Whitcomb (2005): "Non-Response in Student Surveys: The Role of Demographics, Engagement and Personality," Research in Higher Education, 46(2), $127-152$.

Puhani, P. A. (2012): "The treatment effect, the cross difference, and the interaction term in nonlinear "difference-in-differences" models," Economics Letters, 115(1), 85-87.

QuAst, H. (2012): "Studienberechtigte 2006 mit allgemeiner Hochschulreife (nur Abiturientinnen und Abiturienten) 3 1/2 Jahre nach Schulabgang," unveröffentlichte Sonderauswertung, HIS.

Schneider, H., And B. Franke (2014): "Bildungsentscheidungen von Studienberechtigten. Studienberechtigte 2012 ein halbes Jahr vor und ein halbes Jahr nach Schulabschluss," Forum Hochschule 6/2014, DZHW, Hannover.

Schultz, T. W. (1968): "Resources for Higher Education: An Economist's View," Journal of Political Economy, 76(3), 327-347.

State Ministry of Baden-Wuerttemberg (2010): "Ausbau der Hochschulen im Programm "Hochschule 2012" wird 2011 und 2012 fortgeführt," Press Release, 26.10.2010, http://www.baden-wuerttemberg.de/de/service/presse/pressemitteilung/pid/ausbau-derhochschulen-im-programm-hochschule-2012-wird-2011-und-2012-fortgefuehrt/.

Thiel, H., S. L. Thomsen, And B. Büttner (2014): "Variation of learning intensity in late adolescence and the effect on personality traits," Journal of the Royal Statistical Society, Series A, 177(4), 861-892.

Thomsen, S. L. (2015): "The impacts of shortening secondary school duration," IZA World of Labor, 2015(166).

Trautwein, U., and M. Neumann (2008): "Das Gymnasium," in Das Bildungswesen in der Bundesrepublik Deutschland. Strukturen und Entwicklungen im Überblick, ed. by K. S. Cortina, J. Baumert, A. Leschinsky, K. U. Mayer, and L. Trommer, pp. 467-501. Rowohlt, Hamburg.

UNESCO (2012): "International Standard Classification of Education ISCED 2011," UNESCO Institute for Statistics, Montreal. 
A Appendix 


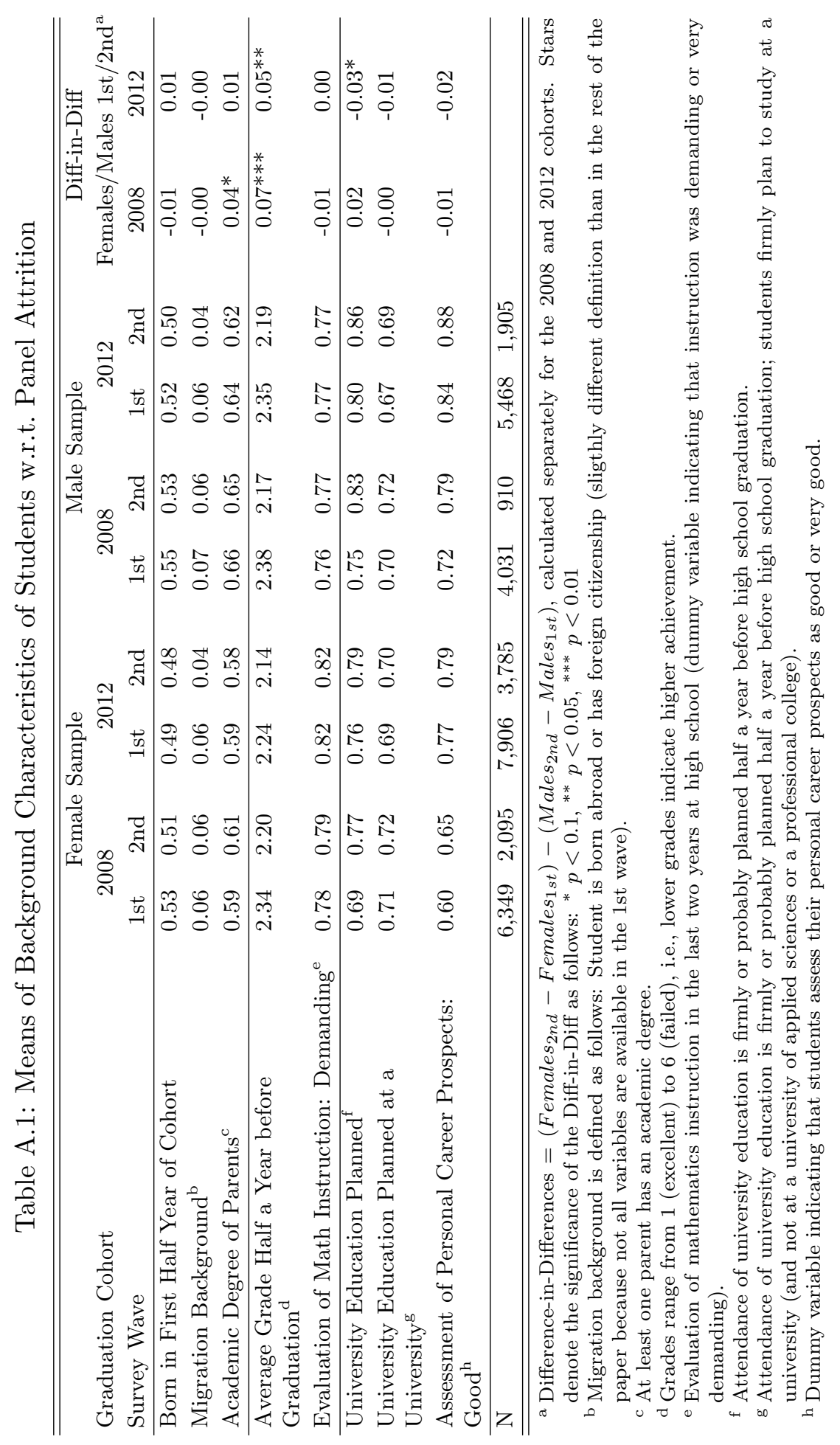


Table A.2: Composition of Treatment and Comparison Groups (Number of Observations)

\begin{tabular}{lcccccccc}
\hline \hline & \multicolumn{3}{c}{ Female Sample } & & \multicolumn{3}{c}{ Male Sample } \\
& TG 1 & TG 2 & TG 3 & & TG 1 & TG 2 & TG 3 \\
\cline { 2 - 4 } \cline { 7 - 8 } & $2008 /$ & $2008 /$ & $2006 /$ & & $2008 /$ & $2008 /$ & $2006 /$ \\
& 2012 & 2012 & 2012 & & 2012 & 2012 & 2012 \\
\hline Saxony-Anhalt & - & - & 302 & & - & - & 144 \\
Mecklenburg-Western Pomerania & - & - & 194 & & - & - & 74 \\
Hamburg & 125 & 125 & - & & 50 & 50 & - \\
Bavaria & 636 & 636 & - & & 351 & 351 & - \\
Lower Saxony & 494 & 494 & - & & 208 & 208 & - \\
Baden-Wuerttemberg & - & 650 & - & & - & 336 & - \\
Bremen & - & 85 & - & & - & 34 & - \\
Berlin & - & 131 & - & & - & 60 & - \\
Brandenburg & - & 151 & - & & - & 86 & - \\
\hline Hesse & 312 & 312 & 302 & & 140 & 140 & 145 \\
Schleswig-Holstein & 153 & 153 & - & & 77 & 77 & - \\
Rhineland-Palatinate & 279 & 279 & - & & 139 & 139 & - \\
Saxony & 363 & 363 & 448 & & 163 & 163 & 175 \\
Thuringia & 260 & 260 & 219 & & 104 & 104 & 100 \\
\hline Treatment Group & 1,255 & 2,272 & 496 & & 609 & 1,125 & 218 \\
Comparison Group & 1,367 & 1,367 & 969 & & 623 & 623 & 420 \\
\hline \hline
\end{tabular}

Table A.3: Introduction of the Reform in the States of the Treatment Group

\begin{tabular}{lccccc}
\hline \hline & $\begin{array}{c}\text { Decision of } \\
\text { Introduction }\end{array}$ & $\begin{array}{c}\text { Imple- } \\
\text { mentation }\end{array}$ & $\begin{array}{c}\text { First Affected } \\
\text { Cohort }\end{array}$ & $\begin{array}{c}\text { Affected } \\
\text { School Types }^{\text {a }}\end{array}$ & $\begin{array}{c}\text { Double Cohort } \\
\text { of Graduates }^{\text {Cha }}\end{array}$ \\
\hline Bavaria & July 2004 & August 2004 & Grade 6 & HS & 2011 \\
Hamburg & June 2003 & August 2003 & Grade 6 & HS and CS & 2010 \\
Lower Saxony & June 2003 & August 2004 & Grade 6 & HS and CS & 2011 \\
\hline \hline
\end{tabular}

a School Types: HS = high school, CS = comprehensive school (only cooperative comprehensive school)

- Source: Own investigation on the basis of law decisions, school laws and information from the state ministries of education. 
Table A.4: Share of Students Dropping Out of Cohort in the Last Two Years of High School

\begin{tabular}{lcccccccccc}
\hline \hline & \multicolumn{1}{c}{ Graduation Cohort } \\
& 2005 & 2006 & 2007 & 2008 & 2009 & 2010 & 2011 & 2012 & 2013 & 2014 \\
\hline Saxony & 0.12 & 0.13 & 0.15 & 0.13 & 0.10 & 0.13 & 0.13 & 0.11 & 0.11 & 0.11 \\
Thuringia & 0.09 & 0.10 & 0.11 & 0.12 & 0.12 & 0.09 & 0.11 & 0.10 & 0.10 & 0.09 \\
\hline Saxony-Anhalt & 0.12 & 0.13 & 0.14 & 0.19 & 0.18 & 0.20 & 0.17 & 0.18 & 0.21 & 0.19 \\
Mecklenburg-Western Pomerania & 0.11 & 0.10 & 0.09 & 0.14 & 0.18 & 0.19 & 0.21 & 0.17 & 0.20 & 0.18 \\
Saarland & 0.11 & 0.10 & 0.08 & 0.10 & 0.14 & 0.08 & 0.14 & 0.14 & 0.18 & 0.18 \\
\hline Hamburg & 0.13 & 0.14 & 0.15 & 0.13 & 0.12 & 0.14 & 0.20 & 0.13 & 0.12 & 0.11 \\
Bavaria & 0.07 & 0.07 & 0.08 & 0.08 & 0.08 & 0.07 & 0.06 & 0.09 & 0.08 & - \\
Lower Saxony & 0.11 & 0.14 & 0.14 & 0.17 & 0.18 & 0.16 & 0.19 & 0.20 & 0.19 & 0.18 \\
\hline Baden-Wuerttemberg & 0.05 & 0.05 & 0.05 & 0.06 & 0.05 & 0.06 & 0.06 & 0.07 & 0.09 & 0.10 \\
Bremen & 0.14 & 0.15 & 0.16 & 0.15 & 0.18 & 0.18 & 0.19 & 0.20 & 0.23 & 0.23 \\
Berlin & 0.15 & 0.15 & 0.17 & 0.14 & 0.17 & 0.17 & 0.14 & 0.25 & 0.25 & 0.24 \\
Brandenburg & 0.11 & 0.09 & 0.09 & 0.11 & 0.09 & 0.10 & 0.10 & 0.17 & 0.15 & 0.20 \\
\hline North Rhine-Westphalia & 0.14 & 0.14 & 0.16 & 0.14 & 0.14 & 0.12 & 0.12 & 0.10 & 0.13 & 0.13 \\
Hesse & 0.13 & 0.12 & - & 0.12 & 0.11 & 0.12 & 0.12 & 0.12 & 0.13 & 0.14 \\
Schleswig-Holstein & 0.12 & 0.12 & 0.11 & 0.12 & 0.12 & 0.08 & 0.13 & 0.13 & 0.13 & 0.12 \\
Rhineland-Palatinate & 0.09 & 0.11 & 0.11 & 0.12 & 0.12 & 0.12 & 0.12 & 0.11 & 0.11 & 0.11 \\
\hline \hline
\end{tabular}

- Share of students who entered the second last year of high school but did not graduate from high school on time (i.e. two years after entry).

- Shares for double graduation cohorts are presented for both cohorts together because separate numbers for G12/G13 students are either not contained or unclear/unreliable in Federal Statistical Office (various years a).

- Shares not available are indicated by -.

- The exceptional high number in Hamburg 2011 could be due to the implementation of a new type of secondary school in 2010/2011 in this state, which could have led to some statistical reporting errors in this year.

- Source: Own calculation on the basis of Federal Statistical Office (various years a).

Table A.5: Introduction of Other Education Reforms in Germany

\begin{tabular}{|c|c|c|c|c|c|}
\hline & $\begin{array}{l}\text { Reduced } \\
\text { School } \\
\text { Duration }\end{array}$ & $\begin{array}{c}\text { Central } \\
\text { Final } \\
\text { Examinations }\end{array}$ & $\begin{array}{l}\text { Tracking } \\
\text { after } \\
\text { Grade } 4\end{array}$ & $\begin{array}{l}\text { Changed } \\
\text { High School } \\
\text { Curriculum }\end{array}$ & $\begin{array}{c}\text { University } \\
\text { Tuition } \\
\text { Fees }^{\mathrm{a}}\end{array}$ \\
\hline \multicolumn{6}{|l|}{ Treatment Group } \\
\hline Bavaria & since 2011 & since 1946 & always & since 2011 & $2006-2012$ \\
\hline Hamburg & since 2010 & since 2005 & always & since 2011 & $2006-2011$ \\
\hline Lower Saxony & since 2011 & since 2006 & since $2012^{\mathrm{b}}$ & since 2008 & $2005-2013$ \\
\hline \multicolumn{6}{|l|}{ Comparison Group } \\
\hline Hesse & since $2012-14$ & since 2007 & always & since 2005 & $2006-2008$ \\
\hline Rhineland-Palatinate & never & never & always & never & never \\
\hline Saxony & always & since 1991 & always & since 2010 & never \\
\hline Schleswig-Holstein & since 2016 & since 2008 & always & since 2011 & never \\
\hline Thuringia & always & since 1991 & always & since 2011 & never \\
\hline
\end{tabular}

a The years correspond to the time when the introduction or elimination of tuition fees was resolved.

b Until 2010, students in Lower Saxony were tracked after grade 6. The 2011 cohort was tracked after grade 5.

- The year indicates the high school graduation cohorts which are affected by the respective reform.

- Source: Own investigations on the basis of school laws, high school regulations, information provided by the state ministries of education and by the standing conference of the ministers of education of the German states. 
Table A.6: Admission Grades in Selected Subjects at Selected Universitities and Universities of Applied Sciences in Bavaria, Lower Saxony and Baden-Wuerttemberg

\begin{tabular}{|c|c|c|c|c|}
\hline & WS 2009/10 & WS 2010/11 & WS 2011/12 & WS $2012 / 13$ \\
\hline \multicolumn{5}{|l|}{ Bavaria: University of Bamberg } \\
\hline Business Administration and Economics & all admitted & all admitted & all admitted & all admitted \\
\hline Psychology & 1.8 & 1.6 & 1.7 & 1.6 \\
\hline Teaching in Primary School & 1.9 & 1.8 & 1.6 & 1.9 \\
\hline Teaching in High School & 1.4 & 1.2 & 1.5 & 1.6 \\
\hline \multicolumn{5}{|c|}{ Bavaria: Ludwig-Maximilians University Munich } \\
\hline Business Administration and Economics & not available & 2.2 & 1.7 & 1.8 \\
\hline Geography & 3.1 & 2.8 & 3.1 & 3.1 \\
\hline Law & 2.2 & 2.3 & 2.2 & 2.1 \\
\hline Psychology & 1.4 & 1.4 & 1.3 & 1.3 \\
\hline Teaching in Primary School & 2.5 & 2.3 & 2.4 & 2.4 \\
\hline \multicolumn{5}{|l|}{ Bavaria: University of Passau } \\
\hline Business Administration and Economics & all admitted & all admitted & 2.6 & 2.4 \\
\hline Business Informatics & all admitted & all admitted & all admitted & all admitted \\
\hline Political Sciences & 2.5 & all admitted & all admitted & all admitted \\
\hline Teaching in Primary School & 2.5 & 2.5 & 2.5 & 2.7 \\
\hline \multicolumn{5}{|c|}{ Bavaria: East Bavarian Technical University Regensburg } \\
\hline Business Administration & 3.0 & 2.6 & 2.7 & 2.4 \\
\hline Business Informatics & all admitted & 3.0 & 3.1 & 2.9 \\
\hline Engineering & 3.0 & 2.9 & 2.7 & 2.7 \\
\hline Social Work & 2.4 & 2.1 & 2.2 & 2.1 \\
\hline \multicolumn{5}{|l|}{ Lower Saxony: Leibniz University Hannover } \\
\hline Biology & 2.3 & 2.3 & 2.1 & 2.4 \\
\hline Business Administration and Economics & 3.1 & 3.0 & 3.3 & 3.4 \\
\hline Business Engineering & 2.6 & 2.4 & 2.6 & 2.9 \\
\hline Engineering & all admitted & all admitted & all admitted & all admitted \\
\hline Geography & 2.7 & 2.7 & 2.6 & 2.4 \\
\hline Law & 3.1 & 2.7 & 3.1 & 3.0 \\
\hline Political Science & 2.5 & 2.7 & 2.7 & all admitted \\
\hline \multicolumn{5}{|l|}{ Lower Saxony: University of Osnabr $\tilde{A} \frac{1}{4} c k$} \\
\hline Biology & 2.1 & 2.1 & 2.1 & 2.2 \\
\hline Business Administration and Economics & all admitted & all admitted & 3.2 & 2.9 \\
\hline Geography & all admitted & 2.8 & 2.8 & all admitted \\
\hline Law & all admitted & 2.8 & 3.3 & all admitted \\
\hline Psychology & 1.6 & 1.5 & 1.4 & 1.4 \\
\hline \multicolumn{5}{|l|}{ Baden-Wuerttemberg: University of Freiburg } \\
\hline Business Administration & 2.7 & 1.9 & 2.1 & 2.7 \\
\hline Geography & 2.0 & 2.0 & 1.9 & all admitted \\
\hline Psychology & 1.2 & 1.1 & 1.1 & 1.3 \\
\hline Teaching German Language & 1.8 & 1.8 & 1.9 & all admitted \\
\hline \multicolumn{5}{|l|}{ Baden-Wuerttemberg: University of Konstanz } \\
\hline Biological Science & not available & 3.5 & 3.2 & 3.2 \\
\hline Law & not available & 3.8 & 3.8 & 3.1 \\
\hline Political Science and Public Management & not available & 2.7 & 2.5 & 2.7 \\
\hline Psychology & not available & 2.7 & 2.1 & 2.0 \\
\hline Sociology & not available & 2.9 & 3.6 & 3.6 \\
\hline Teaching German Language & not available & 3.5 & 2.9 & 3.3 \\
\hline
\end{tabular}

- Admission to university education is based on at least two factors: (1) average grade at high school graduation (ranging between 1 [very good] and 4 [sufficient], i.e., lower grades indicate higher achievement), and (2) number of semesters waiting for university enrollment. Both factors are considered with different weighting, depending on the university. The grades shown above represent admission grades without waiting semesters, i.e., for students attending university in the same year as they graduated from high school.

- WS denotes the winter semester, starting in October of the respective year.

- Double cohorts: 2011 in Bavaria and Lower Saxony, 2012 in Baden-Wuerttemberg.

- Source: Information provided by the respective universities. 
Table A.7: Difference-in-Differences Estimates of Reform Effects, Without Additional Control Variables (Marginal Effects)

\begin{tabular}{|c|c|c|c|c|c|c|}
\hline \multirow{3}{*}{$\begin{array}{l}\text { Pre-/Post-Reform Year } \\
\text { Treatment Group }\end{array}$} & \multicolumn{3}{|c|}{ Female Sample } & \multicolumn{3}{|c|}{ Male Sample } \\
\hline & \multicolumn{2}{|c|}{$2008 / 2012$} & \multirow{2}{*}{$\begin{array}{c}2006 / 2012 \\
\text { TG } 3\end{array}$} & \multicolumn{2}{|c|}{$2008 / 2012$} & \multirow{2}{*}{$\begin{array}{c}2006 / 2012 \\
\text { TG } 3\end{array}$} \\
\hline & TG 1 & TG 2 & & TG 1 & TG 2 & \\
\hline & $(1)$ & $(2)$ & $(3)$ & $(4)$ & $(5)$ & $(6)$ \\
\hline \multirow[t]{2}{*}{ University Educ. (started) ${ }^{\mathrm{a}}$} & $-0.085^{* *}$ & $-0.108^{* * *}$ & $-0.108^{*}$ & -0.045 & -0.038 & -0.047 \\
\hline & $(0.041)$ & $(0.035)$ & $(0.058)$ & $(0.059)$ & $(0.051)$ & $(0.094)$ \\
\hline \multirow[t]{2}{*}{ University Educ. (started/pl.) $)^{\mathrm{b}}$} & 0.003 & -0.004 & -0.029 & -0.052 & -0.052 & 0.001 \\
\hline & $(0.033)$ & $(0.029)$ & $(0.050)$ & $(0.044)$ & $(0.038)$ & $(0.071)$ \\
\hline \multirow[t]{2}{*}{ Vocational Educ. (started) ${ }^{\mathrm{a}}$} & -0.023 & -0.017 & -0.013 & -0.011 & -0.006 & 0.075 \\
\hline & $(0.028)$ & $(0.024)$ & $(0.044)$ & $(0.038)$ & $(0.032)$ & $(0.074)$ \\
\hline \multirow[t]{2}{*}{ Vocational Educ. (started/pl.) ${ }^{\mathrm{b}}$} & -0.008 & 0.001 & 0.014 & 0.036 & 0.033 & 0.034 \\
\hline & $(0.031)$ & $(0.027)$ & $(0.047)$ & $(0.041)$ & $(0.035)$ & $(0.065)$ \\
\hline \multirow[t]{2}{*}{ Internship / Temporary Work ${ }^{\mathrm{c}}$} & $0.050^{* *}$ & $0.063^{* * *}$ & 0.024 & 0.035 & $0.054^{*}$ & 0.027 \\
\hline & $(0.025)$ & $(0.024)$ & $(0.030)$ & $(0.034)$ & $(0.032)$ & $(0.056)$ \\
\hline \multirow[t]{2}{*}{ Voluntary Service / Stay Abroad ${ }^{\mathrm{c}}$} & $0.094^{* * *}$ & $0.074^{* * *}$ & $0.132^{* * *}$ & 0.033 & 0.024 & 0.068 \\
\hline & $(0.033)$ & $(0.029)$ & $(0.050)$ & $(0.044)$ & $(0.037)$ & $(0.098)$ \\
\hline \multirow[t]{2}{*}{ STEM Subjects (narrow def.) ${ }^{d}$} & 0.042 & 0.022 & -0.062 & 0.067 & 0.026 & $-0.201^{* *}$ \\
\hline & $(0.032)$ & $(0.028)$ & $(0.042)$ & $(0.060)$ & $(0.052)$ & $(0.099)$ \\
\hline \multirow[t]{2}{*}{ STEM Subjects (broad def.) ${ }^{d}$} & 0.007 & -0.023 & -0.080 & 0.050 & 0.030 & $-0.213^{* *}$ \\
\hline & $(0.037)$ & $(0.032)$ & $(0.051)$ & $(0.060)$ & $(0.052)$ & $(0.101)$ \\
\hline $\mathrm{N}$ & 2,614 & 3,629 & 1,460 & 1,230 & 1,746 & 635 \\
\hline
\end{tabular}

- Treatment group 1: Bavaria, Hamburg, Lower Saxony.

- Treatment group 2: Bavaria, Hamburg, Lower Saxony, Baden-Wuerttemberg, Berlin, Brandenburg, Bremen.

- Treatment group 3: Mecklenburg-Western Pomerania, Saxony-Anhalt.

- Comparison group 1 and 2: Hesse, Rhineland-Palatinate, Saxony, Schleswig-Holstein, Thuringia.

- Comparison group 3: Hesse, Saxony, Thuringia.

${ }^{a}$ Dependent variable: Dummy indicating actual enrollment in university/vocational education.

b Dependent variable: Dummy indicating actual or firmly planned enrollment in university/vocational education.

c Dependent variable: Dummy indicating participation in the year after high school graduation in an internship or temporary work / in a voluntary service or stay abroad.

d Dependent variable: Dummy indicating actual enrollment or firmly planned enrollment in a STEM university subject (STEM subjects narrowly defined include engineering, natural sciences and mathematics, STEM subjects broadly defined additionally include medical sciences).

- Regressions are separately run for each outcome. Regressions include further explanatory variables (post-reform-dummy, treatment-group-dummy, state dummies), but no sociodemographic and family background characteristics.

- Marginal effects are average marginal effects. Standard errors are shown in parenthesis below marginal effects. Stars denote significance of the estimates as follows: ${ }^{*} p<0.1,{ }^{* *} p<0.05,{ }^{* * *} p<0.01$. 
Table A.8: Robustness Check: Estimations Using 2006 as the Pre-Reform Year (DiD Estimates, Marginal Effects)

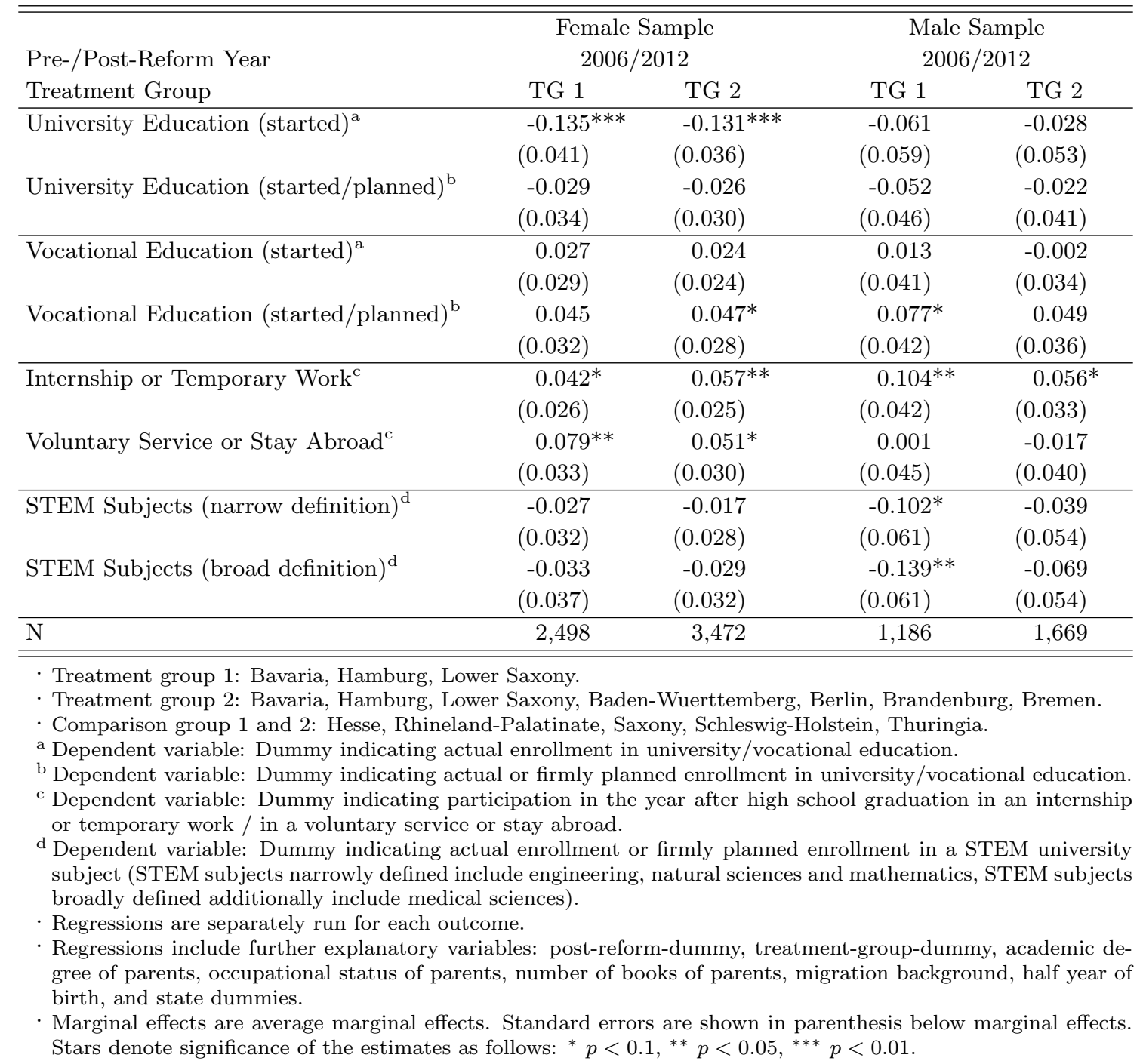




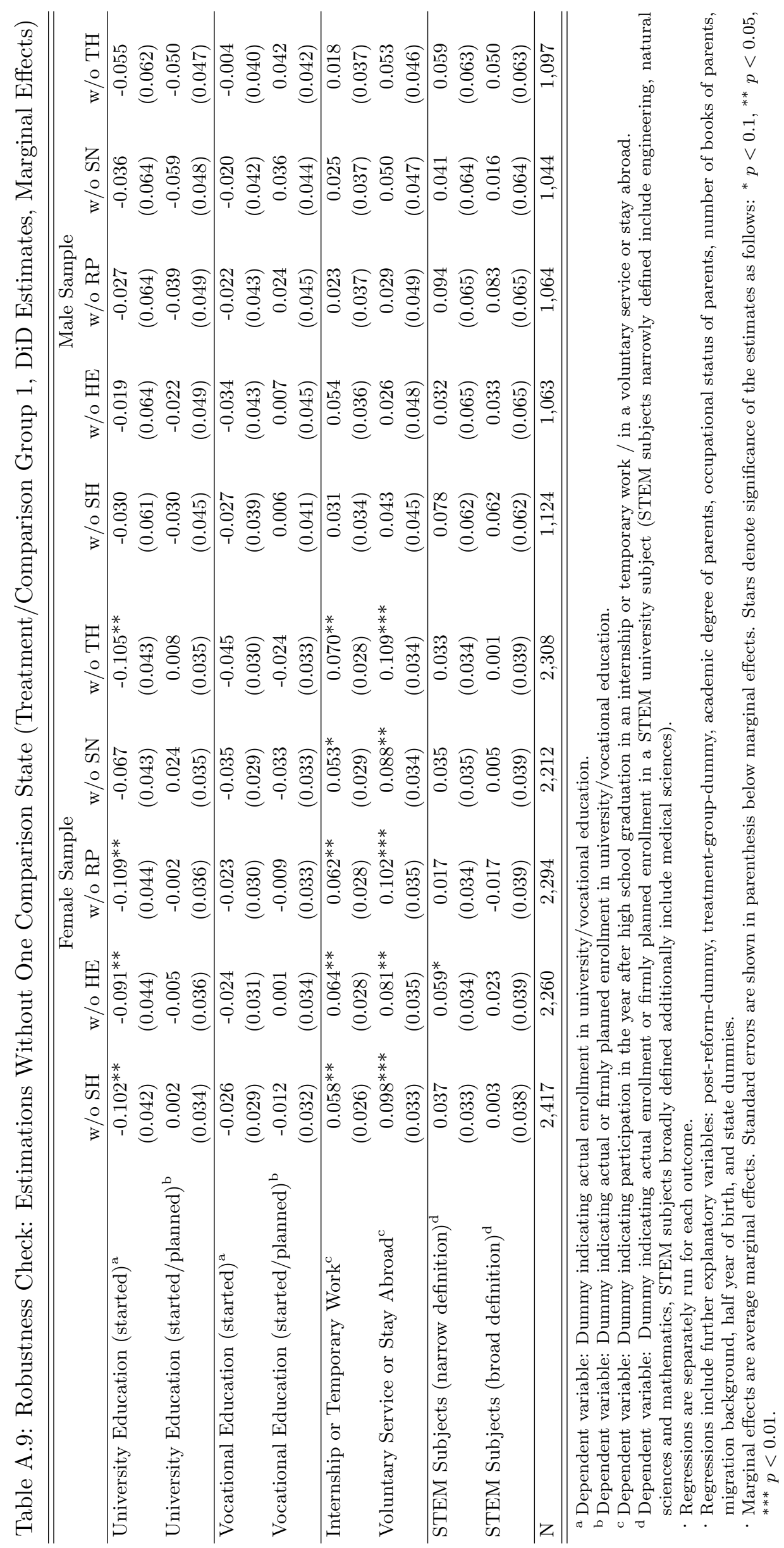


Table A.10: Robustness Check: Placebo Tests (DiD Estimates, Marginal Effects)

\begin{tabular}{|c|c|c|c|c|c|c|}
\hline & \multicolumn{3}{|c|}{ Female Sample } & \multicolumn{3}{|c|}{ Male Sample } \\
\hline & $(1)$ & $(2)$ & $(3)$ & $(1)$ & $(2)$ & $(3)$ \\
\hline & Comp. Gr. & TG $1 /$ & G13 stud. & Comp. Gr. & TG $1 /$ & G13 stud. \\
\hline & West/East & CG 1 & $\mathrm{BB}, \mathrm{BE}$ & West/East & CG 1 & $\mathrm{BB}, \mathrm{BE}$, \\
\hline & $2008 / 12$ & $2006 / 08$ & $\mathrm{BR}, \mathrm{BW}$ & $2008 / 12$ & $2006 / 08$ & $\mathrm{BR}, \mathrm{BW}$ \\
\hline \multirow[t]{2}{*}{ University Education (started) ${ }^{\mathrm{a}}$} & -0.054 & -0.041 & 0.054 & 0.075 & -0.012 & 0.072 \\
\hline & $(0.057)$ & $(0.047)$ & $(0.043)$ & $(0.084)$ & $(0.069)$ & $(0.061)$ \\
\hline \multirow[t]{2}{*}{ University Education (started/pl.) ${ }^{\mathrm{b}}$} & -0.075 & -0.034 & 0.042 & 0.098 & -0.006 & 0.028 \\
\hline & $(0.046)$ & $(0.039)$ & $(0.035)$ & $(0.065)$ & $(0.045)$ & $(0.043)$ \\
\hline \multirow[t]{2}{*}{ Vocational Education (started) $^{\mathrm{a}}$} & $0.075^{*}$ & $0.063^{*}$ & -0.022 & -0.056 & 0.016 & -0.033 \\
\hline & $(0.040)$ & $(0.034)$ & $(0.030)$ & $(0.056)$ & $(0.031)$ & $(0.036)$ \\
\hline \multirow[t]{2}{*}{ Vocational Education (started/pl.) ${ }^{\mathrm{b}}$} & $0.090 * *$ & 0.057 & -0.045 & $-0.106^{*}$ & 0.034 & -0.010 \\
\hline & $(0.043)$ & $(0.037)$ & $(0.033)$ & $(0.059)$ & $(0.037)$ & $(0.038)$ \\
\hline \multirow[t]{2}{*}{ Internship or Temporary Work ${ }^{\mathrm{c}}$} & 0.005 & -0.021 & -0.006 & 0.054 & $0.051^{*}$ & 0.049 \\
\hline & $(0.030)$ & $(0.029)$ & $(0.025)$ & $(0.045)$ & $(0.030)$ & $(0.036)$ \\
\hline \multirow[t]{2}{*}{ Voluntary Service or Stay Abroad ${ }^{\mathrm{c}}$} & -0.019 & -0.012 & -0.025 & -0.073 & -0.015 & -0.027 \\
\hline & $(0.043)$ & $(0.033)$ & $(0.033)$ & $(0.065)$ & $(0.033)$ & $(0.043)$ \\
\hline \multirow[t]{2}{*}{ STEM Subjects (narrow definition) ${ }^{\mathrm{d}}$} & 0.015 & $-0.067^{*}$ & 0.008 & 0.063 & $-0.191 * * *$ & 0.069 \\
\hline & $(0.044)$ & $(0.036)$ & $(0.034)$ & $(0.087)$ & $(0.069)$ & $(0.063)$ \\
\hline \multirow[t]{2}{*}{ STEM Subjects (broad definition) ${ }^{\mathrm{d}}$} & 0.000 & -0.047 & -0.016 & 0.096 & $-0.208^{* * *}$ & 0.076 \\
\hline & $(0.051)$ & $(0.042)$ & $(0.039)$ & $(0.087)$ & $(0.068)$ & $(0.063)$ \\
\hline $\mathrm{N}$ & 1,339 & 1,814 & 2,247 & 613 & 818 & 1,080 \\
\hline
\end{tabular}

(1) Placebo-Test: Using the West German comparison states as treatment group (Hesse, Rhineland-Palatinate, SchleswigHolstein), compared to the East German states from the comparison group (Saxony, Thuringia).

(2) Placebo-Test: Using the original treatment and comparison groups but the years 2006 and 2008 as pre- and post-reform-years.

(3) Placebo-Test: Using the G13 students from the states with a double cohort in 2012 (Baden-Wuerttemberg, Berlin, Brandenburg, Bremen) as treatment group, compared to the original comparison group.

${ }^{a}$ Dependent variable: Dummy indicating actual enrollment in university/vocational education.

b Dependent variable: Dummy indicating actual or firmly planned enrollment in university/vocational education.

${ }^{\mathrm{c}}$ Dependent variable: Dummy indicating participation in the year after high school graduation in an internship or temporary work / in a voluntary service or stay abroad.

${ }^{d}$ Dependent variable: Dummy indicating actual enrollment or firmly planned enrollment in a STEM university subject (STEM subjects narrowly defined include engineering, natural sciences and mathematics, STEM subjects broadly defined additionally include medical sciences).

- Regressions are separately run for each outcome.

- Regressions include further explanatory variables: post-reform-dummy, treatment-group-dummy, academic degree of parents, occupational status of parents, number of books of parents, migration background, half year of birth, and state dummies.

- Marginal effects are average marginal effects. Standard errors are shown in parenthesis below marginal effects. Stars denote significance of the estimates as follows: ${ }^{*} p<0.1,{ }^{* *} p<0.05,{ }^{* * *} p<0.01$. 
Table A.11: Robustness Check: Potential Influence of Other Education Reforms (DiD Estimates, Marginal Effects)

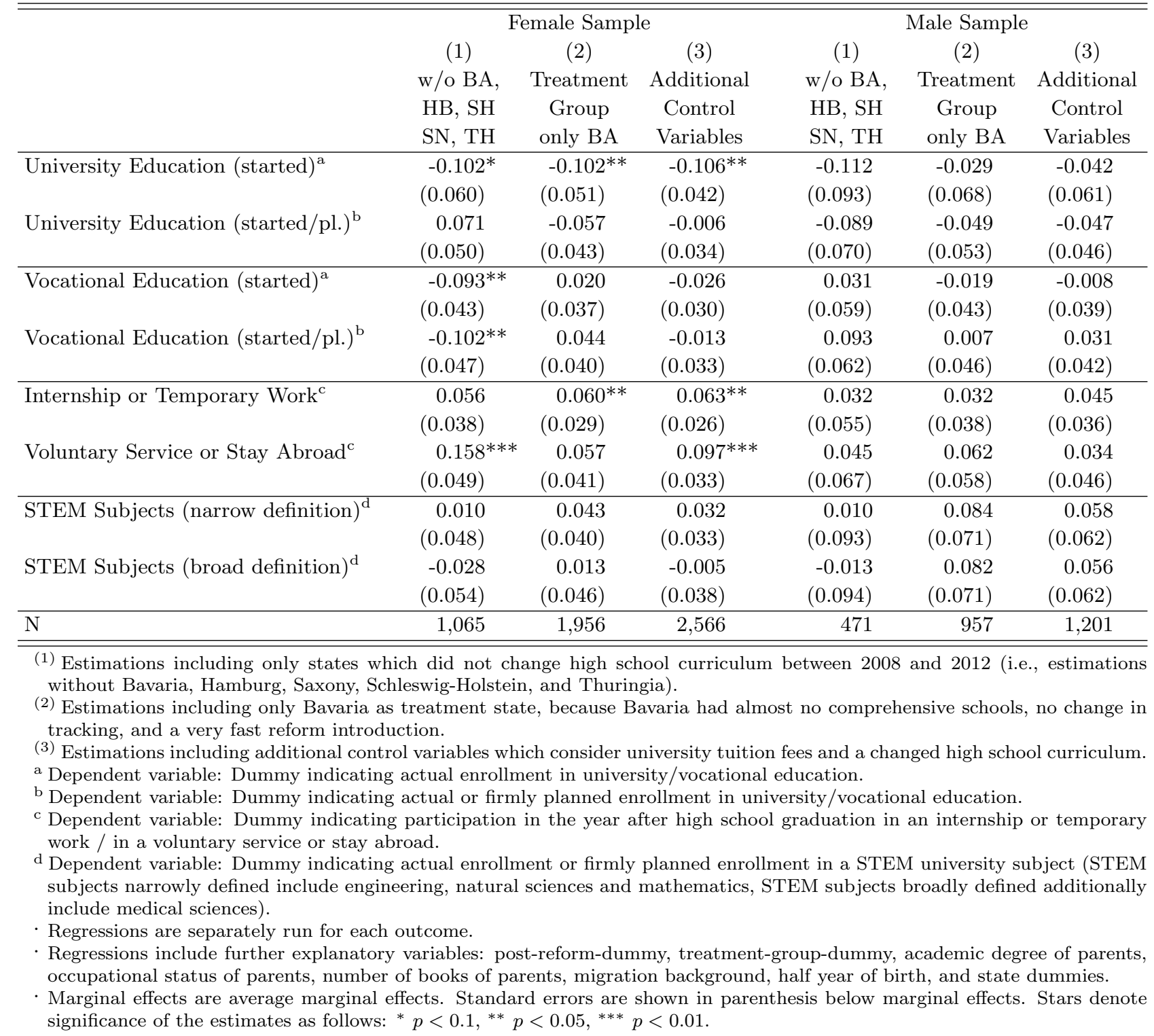


Table A.12: Difference-in-Differences Estimates of Effect Channels: Separate Estimations for Students with Academic and Non-Academic Family Background (Treatment Group 1, Marginal Effects)

\begin{tabular}{|c|c|c|c|c|}
\hline & \multicolumn{2}{|c|}{ Female Sample } & \multicolumn{2}{|c|}{ Male Sample } \\
\hline & $\begin{array}{c}\text { academic } \\
\text { family }^{\mathrm{e}}\end{array}$ & $\begin{array}{c}\text { non-academic } \\
\text { family }^{\mathrm{e}}\end{array}$ & $\begin{array}{c}\text { academic } \\
\text { family }^{\mathrm{e}}\end{array}$ & $\begin{array}{c}\text { non-academic } \\
\text { family }^{\mathrm{e}}\end{array}$ \\
\hline \multicolumn{5}{|c|}{ Postsecondary Education Plans (Half a Year Before High School Graduation) } \\
\hline \multirow[t]{2}{*}{ University Education Planned $^{\mathrm{a}}$} & 0.018 & -0.081 & -0.029 & $-0.140^{*}$ \\
\hline & $(0.039)$ & $(0.057)$ & $(0.049)$ & $(0.078)$ \\
\hline \multicolumn{5}{|c|}{ Difficulties With the Choice of Postsecondary Education (Half a Year Before High School Graduation) ${ }^{b}$} \\
\hline \multirow[t]{2}{*}{ Managing the Many Opportunities } & -0.036 & 0.002 & 0.045 & $0.167^{*}$ \\
\hline & $(0.054)$ & $(0.065)$ & $(0.078)$ & $(0.098)$ \\
\hline \multirow[t]{2}{*}{ Assessment of Labor Market Prospects } & -0.000 & -0.082 & 0.004 & -0.053 \\
\hline & $(0.053)$ & $(0.064)$ & $(0.069)$ & $(0.094)$ \\
\hline \multirow[t]{2}{*}{ Gathering Helpful Information } & -0.014 & -0.037 & -0.010 & -0.009 \\
\hline & $(0.039)$ & $(0.047)$ & $(0.062)$ & $(0.071)$ \\
\hline \multirow[t]{2}{*}{ Assessment of Required Abilities } & 0.045 & 0.006 & 0.046 & 0.025 \\
\hline & $(0.049)$ & $(0.060)$ & $(0.071)$ & $(0.091)$ \\
\hline \multirow[t]{2}{*}{ Unsatisfactory Preparation by School } & -0.044 & -0.001 & -0.045 & $0.150^{*}$ \\
\hline & $(0.048)$ & $(0.060)$ & $(0.072)$ & $(0.088)$ \\
\hline \multirow[t]{2}{*}{ Uncertainty about Own Interests } & 0.023 & 0.044 & -0.078 & 0.112 \\
\hline & $(0.051)$ & $(0.060)$ & $(0.073)$ & $(0.092)$ \\
\hline \multirow[t]{2}{*}{ Uncertainty about Own Abilities } & -0.059 & $0.126^{* *}$ & -0.016 & 0.059 \\
\hline & $(0.054)$ & $(0.063)$ & $(0.073)$ & $(0.092)$ \\
\hline \multirow[t]{2}{*}{ No particular Difficulties } & -0.004 & -0.039 & 0.031 & 0.015 \\
\hline & $(0.019)$ & $(0.024)$ & $(0.039)$ & $(0.065)$ \\
\hline
\end{tabular}

Informed about Postsecondary Education Possibilities (Half a Year Before High School Graduation) ${ }^{c}$

\begin{tabular}{|c|c|c|c|c|}
\hline Feeling Well Informed & $\begin{array}{c}0.154^{* * *} \\
(0.053)\end{array}$ & $\begin{array}{r}0.008 \\
(0.063)\end{array}$ & $\begin{array}{r}0.113 \\
(0.076)\end{array}$ & $\begin{array}{r}-0.069 \\
(0.099)\end{array}$ \\
\hline \multicolumn{5}{|c|}{ Reasons for Delayed Entry into Postsecondary Education (Half a Year After High School Graduation) ${ }^{d}$} \\
\hline Unsuccessful Appl./ Admission Restriction & $\begin{array}{c}0.057^{* *} \\
(0.028)\end{array}$ & $\begin{array}{c}0.069^{*} \\
(0.038)\end{array}$ & $\begin{array}{r}0.049 \\
(0.035)\end{array}$ & $\begin{array}{r}-0.031 \\
(0.041)\end{array}$ \\
\hline Fulfillment of Additional Requirements & $\begin{array}{r}0.029 \\
(0.023)\end{array}$ & $\begin{array}{r}0.037 \\
(0.027)\end{array}$ & $\begin{array}{r}-0.003 \\
(0.025)\end{array}$ & - \\
\hline Earning Money before PSE & $\begin{array}{r}0.017 \\
(0.024)\end{array}$ & & $\begin{array}{c}0.065^{*} \\
(0.037)\end{array}$ & $\begin{array}{r}0.036 \\
(0.042)\end{array}$ \\
\hline Taking a Break before PSE & $\begin{array}{c}0.067^{*} \\
(0.038)\end{array}$ & $\begin{array}{c}0.103^{* *} \\
(0.044)\end{array}$ & $\begin{array}{r}0.046 \\
(0.051)\end{array}$ & $\begin{array}{c}0.117^{*} \\
(0.060)\end{array}$ \\
\hline Indecisiveness about Further Career & $\begin{array}{r}0.036 \\
(0.034)\end{array}$ & $\begin{array}{r}0.027 \\
(0.039)\end{array}$ & & \\
\hline Voluntary Service / Stay Abroad & $\begin{array}{c}0.088^{* *} \\
(0.043)\end{array}$ & $\begin{array}{r}0.051 \\
(0.050) \\
\end{array}$ & $\begin{array}{r}0.021 \\
(0.058)\end{array}$ & $\begin{array}{r}0.085 \\
(0.073)\end{array}$ \\
\hline $\mathrm{N}$ & 1,470 & 1,069 & 730 & 457 \\
\hline \multicolumn{5}{|c|}{$\begin{array}{l}\text { a Dependent variable: Dummy indicating planned enrollment in university education ("Yes, I will definitely/likely } \\
\text { attend university education"). } \\
\text { b Dependent variable: Dummy indicating whether the respective difficulty was present during the decision process } \\
\text { before high school graduation. } \\
\text { c Dependent variable: Dummy indicating that students feel well informed about postsecondary education possibilities } \\
\text { (the upper two categories on a five-point Likert scale). } \\
\text { d Dependent variable: Dummy indicating the reason for delayed entry into postsecondary education. } \\
\text { e A student is defined to come from an academic family if at least one parent has an academic degree. } \\
\text { - Regressions are separately run for each outcome. } \\
\text { Regressions include further explanatory variables: post-reform-dummy, treatment-group-dummy, occupational status } \\
\text { of parents, number of books of parents, migration background, half year of birth, and state dummies. } \\
\text { Marginal effects are average marginal effects. Standard errors are shown in parenthesis below marginal effects. Stars } \\
\text { denote significance of the estimates as follows: }{ }^{*} p<0.1{ }^{* *} p<0.05{ }^{* * *} p<0.01 \text {. }\end{array}$} \\
\hline
\end{tabular}


Table A.13: Stay Abroad During School Education

\begin{tabular}{|c|c|c|c|c|c|c|c|c|c|c|}
\hline & \multicolumn{5}{|c|}{ Female Sample } & \multicolumn{5}{|c|}{ Male Sample } \\
\hline & \multicolumn{2}{|c|}{ Treatm.Gr. 1} & \multicolumn{2}{|c|}{ Treatm.Gr. 2} & Comp.Gr. & \multicolumn{2}{|c|}{ Treatm.Gr. 1} & \multicolumn{2}{|c|}{ Treatm.Gr. 2} & Comp.Gr. \\
\hline & 2010 & 2015 & 2010 & 2015 & $2010 \quad 2015$ & 2010 & 2015 & 2010 & 2015 & $2010 \quad 2015$ \\
\hline 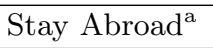 & 0.12 & 0.11 & 0.12 & 0.12 & $\begin{array}{ll}0.10 & 0.10\end{array}$ & 0.10 & 0.09 & 0.11 & 0.10 & $\begin{array}{ll}0.08 & 0.08\end{array}$ \\
\hline $\mathrm{N}$ & 1,739 & 2,482 & 3,499 & 3,867 & $\begin{array}{ll}1,121 \quad 894 \\
\end{array}$ & 1,396 & 2,118 & 2,826 & 3,300 & $869 \quad 745$ \\
\hline
\end{tabular}

